\title{
Endoplasmic reticulum stress induces PRNP prion protein gene expression in breast cancer
}

\author{
Marc-André Déry ${ }^{1,2+}$, Julie Jodoin ${ }^{1,2 \dagger}{ }^{1}$, Josie Ursini-Siegel ${ }^{3}$, Olga Aleynikova ${ }^{3}$, Cristiano Ferrario ${ }^{3}$, Saima Hassan $^{3}$,
} Mark Basik ${ }^{3}$ and Andréa C LeBlanc ${ }^{1,2^{*}}$

\begin{abstract}
Introduction: High prion protein (PrP) levels are associated with breast, colon and gastric cancer resistance to treatment and with a poor prognosis for the patients. However, little is known about the underlying molecular mechanism(s) regulating human PrP gene (PRNP) expression in cancers. Because endoplasmic reticulum (ER) stress is associated with solid tumors, we investigated a possible regulation of PRNP gene expression by ER stress.
\end{abstract}

Methods: Published microarray databases of breast cancer tissues and breast carcinoma cell lines were analyzed for PrP mRNA and ER stress marker immunoglobulin heavy chain binding protein (BiP) levels. Breast cancer tissue microarrays (TMA) were immunostained for BiP and PrP. Breast carcinoma MCF-7, MDA-MB-231, HS578T and HCC1500 cells were treated with three different ER stressors - Brefeldin A, Tunicamycin, Thapsigargin - and levels of PrP mRNA or protein assessed by RT-PCR and Western blot analyses. A human PRNP promoter-luciferase reporter was used to assess transcriptional activation by ER stressors. Site-directed mutagenesis identified the ER stress response elements (ERSE). Chromatin immunoprecipitation (ChIP) analyses were done to identify the ER stressmediated transcriptional regulators. The role of cleaved activating transcription factor $6 \alpha$ ( $\triangle A T F 6 \alpha)$ and spliced X-box protein-1 (SXBP1) in PRNP gene expression was assessed with over-expression or silencing techniques. The role of PrP protection against ER stress was assessed with PrP siRNA and by using Prnp null cell lines.

Results: We find that mRNA levels of BiP correlated with PrP transcript levels in breast cancer tissues and breast carcinoma cell lines. PrP mRNA levels were enriched in the basal subtype and were associated with poor prognosis in breast cancer patients. Higher PrP and BiP levels correlated with increasing tumor grade in TMA. ER stress was a positive regulator of PRNP gene transcription in MCF-7 cells and luciferase reporter assays identified one ER stress response element (ERSE) conserved among primates and rodents and three primate-specific ERSEs that regulated PRNP gene expression. Among the various transactivators of the ER stress-regulated unfolded protein response (UPR), ATF6 $\alpha$ and XBP1 transactivated PRNP gene expression, but the ability of these varied in different cell types. Functionally, PrP delayed ER stress-induced cell death.

Conclusions: These results establish PRNP as a novel ER stress-regulated gene that could increase survival in breast cancers.

\section{Introduction}

Growing evidence indicates that prion protein $(\mathrm{PrP})$ is associated with cellular survival. PrP confers neuroprotection against serum-deprivation [1], Bax protein [2-7], oxidative stress [8], ischemia [9] and PrP mutants or prion-

\footnotetext{
* Correspondence: andrea.leblanc@mcgill.ca

† Contributed equally

${ }^{1}$ Bloomfield Center for Research in Aging, Lady Davis Institute for Medical Research, Sir Mortimer B. Davis Jewish General Hospital, 3755 ch. Côte SteCatherine, Montréal, QC H3T 1E2, Canada

Full list of author information is available at the end of the article
}

like protein Doppel $[10,11]$. The anti-cell death activity of PrP also occurs in peripheral cell types and has been associated with several types of cancer. High levels of PrP induce resistance of MCF-7 breast carcinoma cells to tumor necrosis factor alpha, Tumor Necrosis FactorAlpha-Related Apoptosis-Inducing Ligand (TRAIL)-, and Bax-mediated apoptosis $[4,12,13]$. In estrogen receptor negative breast tumors, PrP expression is associated with chemotherapy resistance [14]. Non-glycosylated and unprocessed non-glycophosphatidyl inositol anchored $\operatorname{PrP}$ is expressed in human pancreatic ductal adenocarcinoma

\section{Biomed Central}


and melanoma cell lines and confers increased proliferation, invasiveness and growth to these cells by interacting with the actin-regulating filamin A protein $[15,16]$. $\operatorname{PrP}$ is also over-expressed in gastric cancers [17], associated with resistance to chemotherapy and poor prognosis [18], and promotes proliferation, invasion and metastasis $[19,20]$. The induction of PrP in gastric cancer is related to hypoxia [21], and $\mathrm{PrP}$ is associated with increased activation of Akt, increased levels of Bcl-2, decreased levels of Bax and a dysregulation of calcium-related genes [22,23]. PrP is also implicated in colon cancer. PrP levels are higher in the most aggressive colon cancer cell lines [24] and in highergrade human colorectal carcinomas [25]. Antibodies against PrP decrease cellular proliferation of colon carcinoma HCT116 cells and also decrease xenograft tumor growth in combination with irinotecan chemotherapy [24]. Furthermore, PRNP gene expression correlates with colorectal cancer recurrence [26].

Preliminary evidence suggests that endoplasmic reticulum (ER) stress may also regulate $P R N P$ gene expression in breast cancer cells. Brefeldin A (BFA) significantly increases PrP levels in breast carcinoma MCF-7 cells [27]. Two other ER stress-inducing compounds, bisphenol A or misfolded surfactant protein $C$, increase PrP levels in mouse testicular Sertoli TTE3 and human embryonic kidney 293 (HEK293) cells $[28,29]$. ER stress initially induces a survival response via the unfolded protein response (UPR); however, prolonged activation leads to apoptosis [30]. The UPR triggers protein refolding [31], attenuation of protein translation [32] and degradation of misfolded proteins [33] via three transmembrane proteins; the activating transcription factor $6 \alpha$ (ATF $6 \alpha$ ), the double-stranded RNA-activated protein kinase-like ER kinase (PERK) and the inositol-requiring enzyme $1 \alpha$ (IRE1 $\alpha)$. Under ER stress, ATF6 $\alpha$ translocates to the Golgi apparatus and is processed by site- 1 and site- 2 proteases to generate cytosolic cleaved ATF6 $\alpha(\triangle \mathrm{ATF} 6 \alpha)$. $\triangle \mathrm{ATF} 6 \alpha$ translocates to the nucleus and activates transcription of ER chaperones, XBP1 and the CCAAT/enhancer-binding protein homologous protein (CHOP) [34,35]. IRE1 $\alpha$ cleaves the mRNA of XBP1 generating a spliced variant (sXBP1) that acts as a transcriptional activator of chaperones and genes involved in protein degradation [36]. PERK phosphorylates the eukaryotic initiation factor $2 \alpha$ (eIF2 $\alpha$ ) and leads to a general decrease in protein translation. Phosphorylation of eIF $2 \alpha$ also causes a preferential translation of the activating transcription factor 4 (ATF4) that induces genes mainly involved in amino acid metabolism and stress response [37]. $\triangle \mathrm{ATF} 6 \alpha$ and sXBP1 recognize an ERSE defined in glucose-regulated genes by a consensus CCAAT-N9-CCACG sequence [35]. In addition, an ATTGG-N-CCACG ERSE-II motif also responds to ER stress [38]. The ERSE motifs can accommodate nucleotide substitutions and operate in a bi-directional manner [35,38-43].
Given that ER stress-mediated activation of the UPR occurs in cancer tissues and cell lines [44,45], we investigated its effect on PRNP gene expression in breast cancer. We found that high mRNA levels of the ER stress marker, immunoglobulin heavy chain binding protein (BiP), correlated with high levels of PrP mRNA in breast cancer tissues and cell lines, both at the RNA and protein level. The high PrP mRNA levels were associated with a poorer prognosis and with the acquisition of a basal phenotype, which is associated with poor patient survival. We then explored the underlying molecular pathway by which ER stress increased PRNP gene expression in the breast carcinoma MCF-7 cell line. Our results showed that ER stress increased endogenous PrP levels through ERSE motifs of the human PRNP promoter. Among the transactivators induced by the three UPR pathways, ATF $6 \alpha$ and sXBP1 were both capable of transactivating PRNP gene expression. Silencing PrP exacerbated ER stress-induced apoptosis in the MCF-7 and MDA-MB-231 cell lines. These results establish PRNP as a novel ER stress-regulated gene and implicate PrP as a prosurvival factor in breast cancer cell lines.

\section{Material and methods}

\section{Tissue microarrays and immunohistochemistry}

All human tissue used for research was obtained by ethical consent of patients [46] and protocol was approved from the Centre Hospitalier de l'Université de Montréal Research Ethics Committee under Canadian Institutes of Health Research (CIHR) guidance rules and in compliance with the Helsinki Declaration. Tissue microarrays (TMAs) were composed of formalin-fixed, paraffin-embedded breast cancer biopsies collected at the Centre Hospitalier de l'Université de Montréal. After re-hydration of the TMA, antigen retrieval was performed by heating the slides in Antigen Unmasking Solution (Vector Laboratories, Burlingame, CA, USA) with a steam oven. Immunohistochemical staining was performed on a Dako Autostainer Plus (Dako, Burlington, ON, Canada). Briefly, Peroxidase Block solution and Protein Block solution was applied on slides before the anti-PrP (1:500, 3F4) or anti-BiP (1:500, Cell Signaling Technologies, Danvers, MA, USA, \#3177) antibodies. The 3F4 epitope-spanning peptide $\mathrm{PrP}_{106-114}$ (Anaspec, Fremont, CA, USA) or BiP blocking peptide (Cell Signaling) were used to adsorb their respective antibody immunoreactivity. Slides were developed with the Envision Flex DAB Chromagen system (Dako, Burlington, ON, Canada) and counterstained with hematoxylin. Slides were mounted in permount and scanned with a Mirax Scan 150 BF/FL Digitizer (Carl Zeiss, Toronto, ON, Canada).

\section{Cell culture and treatments}

MCF-7 cells (ATCC, Manassas, VA, USA) were seeded at $1 \times 10^{6}$ cells per $35 \mathrm{~mm}$ well and treated with $5 \mu \mathrm{g} / \mathrm{mL}$ BFA, $3.25 \mu \mathrm{g} / \mathrm{mL}$ Thps, $2.5 \mu \mathrm{g} / \mathrm{mL}$ TM or their vehicle 
(Biomol Research Laboratories, Plymouth Meeting, PA, USA) in complete cell culture media and in the absence or presence of $1 \mu \mathrm{g} / \mathrm{mL}$ actinomycin $\mathrm{D}$ or $20 \mu \mathrm{g} / \mathrm{mL}$ cycloheximide (Sigma-Aldrich, Oakville, ON, Canada) for the indicated times. Serum deprivation of MCF-7 cells was done for 6 and 18 hours. Basal cell lines MDA-MB231 (ATCC) and HS578T (ATCC) were seeded at $0.8 \times$ $10^{6}$ per $35 \mathrm{~mm}$ well and treated for $20 \mathrm{~h}$ with $10 \mu \mathrm{M}$ 4-Phenyl-Butyric Acid (4-PBA). HCC1500 cells were obtained from ATCC and were cultured at $1 \times 10^{6}$ cells per $35 \mathrm{~mm}$ well in RPMI and 10\% FBS. MDA-MB-231, HS578T and HCC1500 cells were all treated with $5 \mu \mathrm{g} / \mathrm{mL}$ of BFA, Thps or TM.

\section{Protein extraction and western blot analyses}

Cells were lysed on ice in lysis buffer $(150 \mathrm{mM} \mathrm{NaCl}$, $2 \mathrm{mM}$ Ethylenediaminetetraacetic acid (EDTA), 0.5\% Triton X-100, 0.5\% sodium deoxycholate, $50 \mathrm{mM}$ Tris$\mathrm{HCl}, \mathrm{pH} 7.5,38 \mu \mathrm{g} / \mathrm{mL}$ 4-(2-Aminoethyl) benzenesulfonyl fluoride (AEBSF), $0.5 \mu \mathrm{g} / \mathrm{mL}$ leupeptin, $0.1 \mu \mathrm{g} / \mathrm{mL}$ pepstatin, $0.1 \mu \mathrm{g} / \mathrm{mL} \mathrm{N}$-a-p-tosyl-L-lysine chloromethyl ketone hydrochloride, $4 \mathrm{mM}$ sodium orthovanadate, $20 \mathrm{mM}$ sodium fluoride). Protein concentration was determined with the BCA Protein Assay Reagents (Fisher Scientific, Toronto, ON, Canada). Proteins were precipitated in methanol, dried and solubilized in Laemmli sample buffer before being boiled, migrated on SDS-PAGE gel and transferred to PVDF membranes. Membranes were blotted for PrP (3F4 1:2,000), $\beta$-actin (AC-15 1:5,000, Sigma), CHOP (B-3 1:1,000, Santa Cruz Biotechnology, Santa Cruz, CA, USA), BiP (H-129 1:250, Santa Cruz Biotechnology), ATF6 $\alpha$ (1:500, Imgenex, San Diego, CA, USA), eIF2 $\alpha$ (1:500, Cell Signaling), phosphorylated eIF2 $\alpha$ (peIF2 $\alpha$ Ser51 1:500, Cell Signaling), XBP1 (M-186 1:200, Santa Cruz Biotechnology), Bax (2D2 or N-20 1:2,000 or 1:3,000, Sigma), $\operatorname{Bim}$ (Y-36 1:5,000, Epitomics, Burlingame, CA, USA) and Bcl-2 (100 1:250, Santa Cruz Biotechnology). Immunoreactivity was revealed with horseradish peroxidase (HRP) or alkaline phosphatase secondary antibodies (1:5,000, GE Healthcare Bio-Sciences, Piscataway, NJ, USA or Jackson ImmunoResearch Laboratories, West Grove, PA, USA) and ECL or NBT/BCIP (GE Healthcare, EMD Millipore, Billerica, MA, USA, or Promega, Madison, WI, USA).

\section{RT-PCR analyses of PrP, spliced XBP1, ATF6 $\alpha$ and $\beta$-actin mRNA}

Total RNA was isolated from MCF-7 with the TRIzol reagent according to the manufacturer's protocol (Invitrogen Life Technologies, Burlington, ON, Canada). Reverse transcription was accomplished with avian myeloblastosis virus (AMV) reverse transcriptase (Roche Diagnostics, Laval, QC, Canada) and Oligo $\mathrm{dT}_{12-18}$ (GE Healthcare) while the PCR amplification were done with FideliTaq DNA polymerase (USB Corporation, Cleveland, $\mathrm{OH}$,
USA). The primers were: PrP-For 5'-GGAACAAGCCG AGTAAGCTAAAA ACCAACATGAAGCAC-3', PrP-Rev 5'-GGTTGTGGTGACCGCGTGCTGCTTGATTG-3', XBP1-For 5'-GGGTCCAAGTTGTCCAGAATGC-3', XBP1-Rev 5'-TTACGAGAGAAAACTCATGGC-3' [47], $\beta$-actin-For 5'-CTGGAACGGTGAAGGTGACA-3' and $\beta$-actin-Rev 5'-AAGGGACTTCCTGTAACAATGCA-3', ATF6 $\alpha$-For 5' TGGGGGAGTCACACAGCTCCC 3', ATF6 $\alpha$-Rev 5' AGCTGCCGCTTCAGTGTTCCA 3'. The PCR conditions were 1 cycle of 5 minutes at $95^{\circ} \mathrm{C}, 25$ cycles of $30 \mathrm{sec}$ at $95^{\circ} \mathrm{C}, 1$ minute at $50^{\circ} \mathrm{C}$ and 1 minute at $68^{\circ} \mathrm{C}$, followed by 1 cycle of 5 minutes at $68^{\circ} \mathrm{C}$.

\section{Luciferase assays}

The pGL-538 and pGL-214 human PrP promoter constructs were kindly provided by Dr. J. Collinge (MRC Prion Unit, London, UK) and contain 538 or 214 nucleotides upstream of the start site and 125 nucleotides of exon I into the pGL2-Basic vector [48]. The pRL-TK vector was obtained from Promega (Madison). Point mutations in pGL-538 were performed using QuikChange SiteDirected Mutagenesis (Agilent Technologies, Santa Clara, CA, USA). The following forward primers were used to produce point mutations in ERSE-like 5'-AAGATGATTTTTACAGTCAATGAGATCTAG AAGGGAGCGATGGCACCCGCAGG-3', in ERSEa 5'-CGGCCCTG CTTGGCAGCGCGATCGACTTTAACTTAAACCTC GGC-3', in ERSE-II 5'-GCGCGGCAATTGGTCATATG GCCGACCTCCGCCCGCG-3' and in ERSEb 5'-GCGG CAATTGGTCCCCGCATATGTCTCCGCCCGCGAG CGCCG-3'. The generated mutants were verified by restriction enzyme digestion because the mutations introduced a PvuI site in the ERSEa mutant, $\mathrm{XbaI}$ and $\mathrm{Bgl} I I$ sites in the ERSE-like mutant and NdeI site in the ERSE-II and ERSEb mutants. HEK293T cells (ATCC) seeded at 0.6 $\times 10^{6}$ cells $/ 35 \mathrm{~mm}$ well were transfected or co-transfected with $4 \mu \mathrm{g}$ of pGL-214, pGL-538 or mutated pGL-538 and $0.35 \mu \mathrm{g}$ of pRL-TK in Lipofectamine ${ }^{\mathrm{TM}} 2000$ reagent (Invitrogen). ER stressors or the DMSO control was added for $6 \mathrm{hrs}, 24 \mathrm{hrs}$ after the transfection. Proteins were recuperated as recommended in the Dual-Luciferase Reporter Assay System (Promega). Firefly luciferase and Renilla luciferase activities were measured and expressed as the relative luminescence units (RLU) corresponding to the ratio of the firefly luciferase activity over the Renilla luciferase activity per $\mu \mathrm{g}$ of proteins. Data were normalized to luciferase activity levels obtained from wild type PRNP promoter.

\section{Overexpression or silencing of proteins}

Co-transfections of pGL-538 (400 ng/24-well) and 400 ng/24-well pCGN-IRES-EGFP, pCGN-HA-splicedXBP1IRES-EGFP (both kindly provided by Dr R. Kaufman, U. Michigan), or pCGN-ATF6 $\alpha$ (1-373) (Addgene plasmid 
27173) [49] with the $75 \mathrm{ng} / 24$-well pRL-TK vector were done with Lipofectamine $\mathrm{T}^{\mathrm{TM}} 2000$ (Invitrogen) in HEK293 cells for 24 hrs before assessing Firefly and Renilla luciferase with the Dual-Luciferase Reporter Assay System (Invitrogen). Both XBP1 and ATF6 $\alpha$ upregulated the Renilla luciferase promoter so the Firefly luciferase data were expressed relative to the Renilla luciferase of pCGN-EGFP and pRL-TK transfected cells. RT-PCR was conducted to confirm the over-expression of ATF $6 \alpha$ and XBP1. For silencing of ATF $6 \alpha$ and XBP1, HEK293 cells were co-transfected with $75 \mathrm{ng} / 24$-well of pRL-TK, 800 ng/24-well of pGL-538, and 200 nM siRNAs against human ATF6 $\alpha$ (siATF6 $\alpha$ ) from Santa Cruz Biotechnology (pool of three target specific siRNAs: sc-37699) and from Dharmacon (Dharmacon, Lafayette, CO, USA) (one siRNA: On-TARGETplus human ATF6 $\alpha$ (22926) siRNA) or human XBP1 siRNAs from Santa Cruz Biotechnology (pool of three target specific siRNAs: sc-38627) and Dharmacon (one siRNA: On-TARGETplus human XBP1 (7494) siRNA). The si Control (siCtl) was a scrambled siRNA from Santa Cruz Biotechnology (sc-37007) and all transfections were done with Lipofectamine ${ }^{\mathrm{TM}} 2000$. The siRNAs were transfected for 24 hrs and then ER stressors added for 6 hrs before luciferase assays.

For over-expression of proteins in MCF-7 cells, the constructs $(4 \mu \mathrm{g} / 6$-well) were transfected with Lipofectamine $^{\mathrm{TM}} 2000$. The $\mathrm{pCep} 4 \beta-\mathrm{PrP}$ construct was previously described [2], and the pCGN-HA-ATF4-IRES-EGFP construct was a kind gift from Dr R. Kaufman [50]. Proteins were extracted after 24 hrs.

For silencing with siRNAs (at concentrations indicated above), HEK 293 cells were transfected with Lipofectamine $^{\mathrm{TM}}$ 2000, MDA-MB-231 and HS578T were transfected with Lipofectamine ${ }^{\mathrm{TM}}$ RNAiMAX (Invitrogen), and MCF-7 cells were transfected by nucleofection (Amaxa Kit V, VCA-1003, Lonza, Basel, Basel-Stadt, Switzerland) following the manufacturer's protocol, as these methods were the best for each specific cell line. The siRNAs against PrP (siPrP) were human PrP-targeting siRNA from Santa Cruz Biotechnology (sc-36318) or the Dharmacon On-TARGETplus human PrP (5621) siRNA. MCF-7 cells were transfected for 24 hrs before submitting them to an ER stressor for $18 \mathrm{hrs}$ before RNA or protein extraction. MDA-MB-231 and HS578T cells were transfected for 24 hrs before RNA or protein extraction.

\section{Chromatin immunoprecipitation assay (ChIP)}

The ChIP assays were performed as described previously [51] with some modifications. MCF-7 cells treated for three hours with $5 \mu \mathrm{g} / \mathrm{mL}$ BFA or DMSO were harvested by trypsinization and cross-linked in 1\% formaldehyde. Nuclei were lysed for 20 minutes on ice in sonication buffer $(50 \mathrm{mM}$ Hepes pH 7.4, $140 \mathrm{mM} \mathrm{NaCl}, 1 \mathrm{mM}$ EDTA, 1\% Triton X-100, 0.1\% sodium deoxycholate, 1\%
SDS, protease inhibitors). Nuclear lysates were sonicated and pre-cleared with Protein G-Sepharose (Sigma) precoated with $1 \mu \mathrm{g} / \mathrm{mL}$ sonicated salmon sperm nuclei (Sigma), $1 \mathrm{mg} / \mathrm{mL}$ BSA. Chromatin was then incubated with pre-coated Protein G-Sepharose and ATF6, XBP1 or control IgG antibodies $(3 \mu \mathrm{g})$. After washing, the immunoprecipitates were eluted with $50 \mathrm{mM} \mathrm{NaHCO}_{3}$, $1 \%$ SDS, $1 \mathrm{mM}$ EDTA and $50 \mathrm{mM}$ Tris- $\mathrm{HCl} \mathrm{pH} 8.0$ and cross-linking reversed. The DNA was purified and used for PCR amplification.

\section{Cell death assays}

For PrP silencing, siRNAs were transfected for 30 minutes, then ER stress was done for $6 \mathrm{hrs}$ and removed, cell death assays were conducted after another $18 \mathrm{hrs}$. For the MCF7 cells, $0.1 \mu \mathrm{g} / \mathrm{mL}$ BFA, $1 \mu \mathrm{g} / \mathrm{mL}$ Thps and $5 \mu \mathrm{g} / \mathrm{mL}$ TM was used. For MDA-MB-231 and HS578T cells, 5 and $10 \mu \mathrm{g} / \mathrm{mL}$ of each ER stressors was used. The chromatin was stained for 20 minutes with $1 \mu \mathrm{g} / \mathrm{mL}$ Hoechst 33342 (Sigma). Caspase activity was measured with the SR Fluorochrome-labeled inhibitors of caspases (FLICA) poly caspase kit (AbD Serotec, Raleigh, NC, USA) according to the manufacturer's instructions.

\section{Molecular mechanism of PrP protection}

Prior to seeding, MCF-7 cells were transfected with scrambled or siPrP by nucleofection (Amaxa Kit V, VCA-1003, Lonza) following the manufacturer's protocol. Cells were treated with ER stressing drugs $5 \mu \mathrm{g} / \mathrm{ml} \mathrm{BFA}$, $1 \mu \mathrm{g} / \mathrm{ml}$ Thps or $5 \mu \mathrm{g} / \mathrm{ml}$ TM for $6 \mathrm{~h}$. Cells were lysed (150 mM NaCl, 50 mM Tris- $\mathrm{HCl}$ pH 8.0, 5 mM EDTA pH 8.0, 1\% CHAPS or NP-40, $38 \mu \mathrm{g} / \mathrm{mL}$ AEBSF, $0.5 \mu \mathrm{g} / \mathrm{mL}$ Pepstatin A, $1 \mu \mathrm{g} / \mathrm{ml}$ TLCK and $0.5 \mu \mathrm{g} / \mathrm{ml}$ Leupeptin) at 6, 12 or $18 \mathrm{~h}$ post-treatment and protein content was quantified using the BCA method. Protein $(500 \mu \mathrm{g})$ was immunoprecipitated using Protein G-coupled beads and the active Bax-specific 6 A7 antibody (1:100 or $5 \mu \mathrm{g} / \mathrm{ml}$, BD Pharmingen, Mississauga, ON, Canada). Beads were washed, resuspended in loading buffer, boiled and immunoprecipitated Bax levels were assessed by Western blot. Lysates were simultaneously used to investigate $\mathrm{BiP}, \mathrm{Bax}, \mathrm{Bim}, \mathrm{Bcl}-2$ and $\beta$-actin levels by Western blot. Proteins from untransfected cells lysed in CHAPS or NP-40-containing lysis buffers acted as negative and positive control for Bax activation.

\section{Statistical analysis}

Previously published data and PrP scores in low and high BiP TMAs were compared with a Student $t$-test two-way assuming equal variance. To compare PrP and BiP scores of each tumor grade, means were compared using nonparametric Kruskal-Wallis test with the InStat 3.1a software (GraphPad Software Inc., La Jolla, CA, USA). Correlations were performed with Spearman's rank correlation with InStat. For all other statistical significance tests an analysis 
of variance (ANOVA) followed by Scheffé's or TukeyKramer post-hoc test was performed using StatView software (SAS Institute Inc., Cary, NC, USA). A $p$-value of less than 0.05 was taken as a significant difference.

\section{Results}

Higher levels of PrP mRNA in breast tumors are associated with a poor prognosis

Data analyses of three publically available breast cancer mRNA microarray databases [52-54] revealed that higher PrP mRNA levels were significantly associated with lower estrogen (ERS) and progesterone (PR) receptor levels and higher tumor grades (Table 1). One study indicated an earlier age of diagnosis in high PrP mRNA tumors [53]. Moreover, a statistically significant association was observed between high PrP levels and metastatic events (Table 1). The percentage of individuals with a metastatic event within five years doubled in the high PrP group and the number of years that individuals remained lung and bone metastasis free decreased significantly by one year in the high PrP group. Analyses of mRNA microarrays of 56 breast carcinoma cell lines [55] showed that basal breast cancer cell lines have higher PrP mRNA levels than luminal cell lines (Figure 1). Together, these results indicate that high PrP mRNA levels are associated with poorer prognosis breast cancers.

\section{ER stress is associated with increased BiP and PrP levels} in human breast cancer biopsies

To evaluate if ER stress is associated with high PrP levels, we investigated the ER stress marker BiP (also known as GRP78) and PrP levels in breast cancer TMA by immunohistochemistry. PrP was detected in the cytoplasm and in the nucleus of epithelial cells, infrequently found at the cell surface of epithelial cells and was absent in stromal cells (Figure 2A). On the other hand,
BiP staining was only found in the cytoplasm, as expected for this ER-resident protein (Figure 2B). Immunoreactivity was eliminated in protein-adsorbed antibodies (Figure 2C, D). The tissue cores were individually analyzed by a trained pathologist (OA) and scored as 0 (absence of staining), 1 (mild staining), 2 (moderate staining) and 3 (high staining). PrP immunostaining was only observed in tumor tissue cores and not in normal tissue cores whereas $\mathrm{BiP}$ was present in both normal and tumor tissue cores (Figure 2E). Higher PrP and BiP levels segregated with a higher tumor grade (Figure 2F, G). The high BiP-expressing tumor cores had higher PrP levels than low BiPexpressing tumors indicating that ER stress is associated with increased $\operatorname{PrP}$ in these tissues (Figure $2 \mathrm{H}$ ). Furthermore, the levels of PrP correlated significantly with the loss of estrogen receptor (Spearman $\mathrm{r}=-0.2036, P=$ 0.0025 ) and progesterone receptor (Spearman $r=-0.2297$, $P=0.0007$ ) negative tumors (Figure 2I, J). In contrast, no significant correlation was observed between the levels of $\mathrm{BiP}$ and the estrogen and progesterone receptor status. Supporting these results, analysis of the mRNA microarray data [52-54] indicated that in two of three studies, highBiP expressing tumors were associated with higher PrP mRNA levels (Table 2). Furthermore, higher BiP mRNA in breast carcinoma cell lines correlated with a higher PrP mRNA level (Table 2). Overall, these results suggest that ER stress is associated with increased PRNP gene expression in human breast cancer tumors with a basal subtype and poor outcome in human patients.

\section{ER stress transcriptionally increases PrP levels in MCF-7 cells}

To experimentally assess if ER stressors up-regulate PRNP gene expression in breast cancer cells, we assessed the luminal subtype breast carcinoma MCF-7 cell line, which lacks endogenous PrP expression under steady state conditions. MCF-7 cells were exposed to three different ER

Table 1 Association between PrP mRNA levels and breast cancer parameters

\begin{tabular}{|c|c|c|c|c|c|c|c|c|c|}
\hline & \multicolumn{3}{|c|}{ Chin et al., 2006} & \multicolumn{3}{|c|}{ van der Vijver et al., 2002} & \multicolumn{3}{|c|}{ Minn et al., 2005} \\
\hline & $\begin{array}{l}\text { Low PrP } \\
(n=59)\end{array}$ & $\begin{array}{c}\text { High PrP } \\
(n=59)\end{array}$ & & $\begin{array}{l}\text { Low PrP } \\
(n=147)\end{array}$ & $\begin{array}{l}\text { High PrP } \\
(n=147)\end{array}$ & & $\begin{array}{l}\text { Low PrP } \\
(n=49)\end{array}$ & $\begin{array}{l}\text { High PrP } \\
(n=49)\end{array}$ & \\
\hline & Mean \pm SD & Mean \pm SD & $P$-value & Mean \pm SD & Mean \pm SD & $P$-value & Mean \pm SD & Mean \pm SD & $P$-value \\
\hline PrP & $0.75 \pm 0.1$ & $1.49 \pm 0.4$ & $<0.001^{*}$ & $0.72 \pm 0.2$ & $1.53 \pm 0.6$ & $<0.001^{*}$ & $0.63 \pm 0.1$ & $1.38 \pm 0.4$ & $<0.001^{*}$ \\
\hline ERS & $0.81 \pm 0.4$ & $0.47 \pm 0.5$ & $<0.001^{*}$ & $0.90 \pm 0.3$ & $0.63 \pm 0.5$ & $<0.001^{*}$ & $0.82 \pm 0.4$ & $0.33 \pm 0.5$ & $<0.001^{*}$ \\
\hline$P R$ & $0.68 \pm 0.5$ & $0.45 \pm 0.5$ & $0.012^{*}$ & \multicolumn{3}{|c|}{ Not Available } & $0.59 \pm 0.5$ & $0.27 \pm 0.4$ & $0.001^{*}$ \\
\hline Grade & $2.29 \pm 0.7$ & $2.53 \pm 0.7$ & $0.049^{*}$ & $2.06 \pm 0.8$ & $2.23 \pm 0.8$ & 0.068 & \multicolumn{3}{|c|}{ Not Available } \\
\hline Age & $55.1 \pm 16$ & $55.1 \pm 14$ & 0.995 & $44.5 \pm 5$ & $43.5 \pm 6$ & 0.129 & $58.7 \pm 14$ & $53.3 \pm 12$ & $0.050^{*}$ \\
\hline $\begin{array}{c}\text { 5Y Met } \\
\text { Event }\end{array}$ & \multicolumn{6}{|c|}{$\%$ with metastasis after 5 yrs $1=$ yes, $0=$ no } & $0.19 \pm 0.4$ & $0.44 \pm 0.5$ & $0.029^{*}$ \\
\hline Met Event & \multicolumn{6}{|c|}{$\%$ with metastatic event independent of time } & $0.24 \pm 0.4$ & $0.42 \pm 0.5$ & 0.085 \\
\hline MFS & \multicolumn{6}{|c|}{$\%$ with metastasis free survival (yrs) } & $5.63 \pm 2.0$ & $4.68 \pm 2.5$ & 0.064 \\
\hline LM Event & \multicolumn{6}{|c|}{ Lung metastasis } & $0.05 \pm 0.2$ & $0.28 \pm 0.5$ & $0.007^{*}$ \\
\hline LMFS & \multicolumn{6}{|c|}{ Lung metastasis free survival (yrs) } & $6.02 \pm 1.8$ & $4.96 \pm 2.6$ & $0.037^{*}$ \\
\hline BM Event & \multicolumn{6}{|c|}{ Bone metastasis } & $0.13 \pm 0.3$ & $0.21 \pm 0.4$ & 0.362 \\
\hline BMFS & \multicolumn{6}{|c|}{ Bone metastasis free survival (yrs) } & $5.83 \pm 1.9$ & $4.82 \pm 2.5$ & $0.046^{*}$ \\
\hline
\end{tabular}




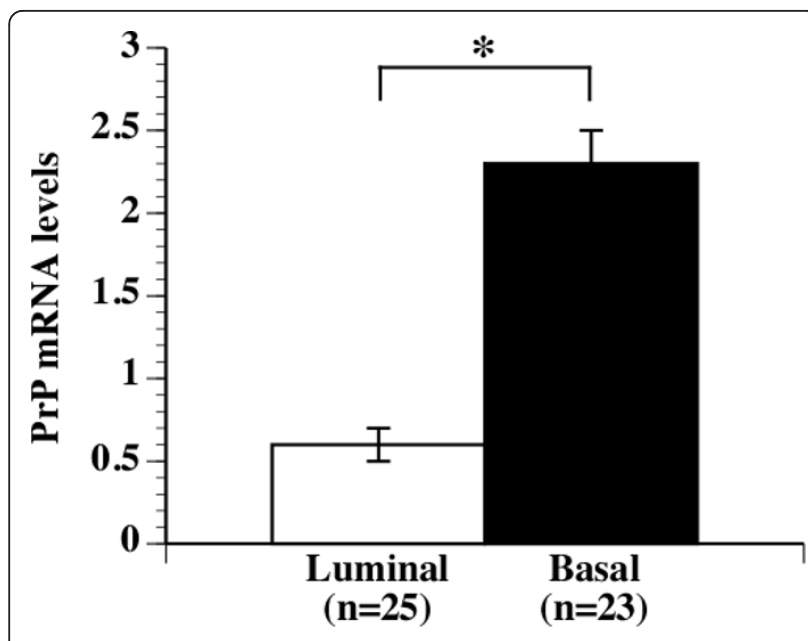

Figure 1 PrP levels are increased in basal breast carcinoma cell lines. PrP mRNA levels were averaged in basal or luminal tumor cell lines. Data represent mean \pm SEM of PrP. * indicates $p \leq 0.05$ between both groups.

stressors: Golgi-disaggregating BFA, N-linked glycosylation inhibitor Tunicamycin (TM), and ER Ca-ATPase family (SERCA) inhibitor Thapsigargin (Thps). Each ER stressor increased PrP levels in a dose-dependent manner within $18 \mathrm{hrs}$ of treatment (Figure 3A). PrP accumulated as immature glycosylated proteins (28 to $33 \mathrm{kDa}$ ) with BFA, as unglycosylated $(25 \mathrm{kDa})$ protein with $\mathrm{TM}$, and as unglycosylated, immature, and mature ( 34 to $36 \mathrm{kDa}$ ) glycosylated proteins with Thps. Increased BiP protein levels confirmed induction of the ER stress response with the BFA, TM and Thps treatments. The ER stress-mediated up-regulation of PrP appeared specific since serum-deprivation of MCF-7 cells for 18 hrs did not increase PrP levels (Figure 3B). ER stressors increased PrP mRNA levels within six hours of treatment in MCF-7 cells with concomitant splicing of XBP1 (sXBP1), although sXBP1 was more prominent in the BFA-treated MCF-7 cells (Figure $3 C)$. ER stress was further confirmed by Western blots showing an increase of ERP44, GRP94, ERP72 and BiP, proteins known to be up-regulated in ER stress (Figure 3D). Furthermore, the transcriptional inhibitor actinomycin D (Act D) or the translational inhibitor, cycloheximide (CHX) strongly inhibited the ER stress-mediated increase of PrP levels and the increase of the ER stress-related protein CHOP (Figure 3E). Together, these results show that ER stress of the luminal breast carcinoma MCF-7 cell line increases PRNP gene transcription.

\section{PRNP gene expression is up-regulated by ER stress in} basal carcinoma cell lines

A comparison of basal breast carcinoma cell lines, MDA-MB-231, HS578T and HCC1500, with luminal MCF-7 cells revealed a high level of PrP in the MDA-
MB-231 and HS578T cell lines but not in the HCC1500 basal cell line. However, BFA, TM and Thps increased the levels of PrP and BiP in the HCC1500 cell line (Figure 4B) as observed in the luminal MCF-7 cell line (Figure 3A). Treatment of MDA-MB-231 and HS578T cells with 4-phenyl butyric acid (4-PBA), an inhibitor of ER stress [56], decreases both BiP and PrP levels suggesting that $\operatorname{PrP}$ is increased by intrinsic ER stress in these two basal carcinoma cell lines (Figure 4C). Nevertheless, the three pharmacological ER stressors further increased both BiP and PrP levels in MDA-MB-231 and HS578T cells (Figure 4D). Together, these results show that intrinsic or exogenous ER stress up-regulates PRNP gene expression in basal breast carcinoma cell lines.

\section{Identification of four ER stress response elements in PRNP promoter}

We identified three potential ER stress response elements (ERSE) and one ERSE-II motif in the human PRNP promoter using the transcription factor database TRANSFAC and by manually scanning the PRNP promoter (EMBL accession no. AJ289875) [48] (Figure 5A). No consensus UPR element (UPRE) or amino-acid-regulatory element (AARE) was found in the PRNP promoter. Two ERSE motifs, named here ERSEa and ERSEb to easily discriminate between them, were located at nucleotides -89 to -71 and at -20 to -2 , respectively. ERSEa was in the opposite orientation and had a $\mathrm{T}$ to A substitution (CCAAT to CCAAa) compared to the ERSE consensus sequence. The ERSEb nucleotide sequence also contained two CG substitutions (CCACG to CgACc). One non-conventional ERSE (ERSE-like) motif, located from -231 to -196 and predicted by TRANSFAC, contained N26 rather than the canonical N9 of the glucose-regulated proteins CCAAT-N9-CCACG ERSE consensus sequence [35]. One canonical ERSE-II motif was contained within ERSEb (-20 to -10). Compared to the ERSE-II consensus sequence (ATTGG-N-CCACG), the ERSE-II motif in the PRNP gene promoter had an A to $\mathrm{C}$ substitution (CCACG to $\mathrm{CCCCG}$ ).

PRNP transcriptional activation was assessed with the PRNP promoter-luciferase reporter constructs pGL-214 and pGL-538, which contain 214 or 538 nucleotides preceding the major transcriptional start site of PRNP, as well as 125 nucleotides of the non-coding exon I [48]. Under normal conditions, substantial luciferase activity was detected in pGL-214- and pGL-538-transfected HEK293T cells, compared to the pGL2 empty vector-transfected cells (Figure $5 \mathrm{~B}$ ). The three ER stressors increased the luciferase activity in pGL-214- and pGL-538-transfected cells by 1.7 - to 2.6-fold. Point mutations in the ERSE-like, ERSEa, ERSE-II and ERSEb motifs (Figure $5 \mathrm{C}$ ) considerably reduced the constitutive PRNP promoter activity (Figure 5D). This has also been observed with other ER stress regulated gene promoters 


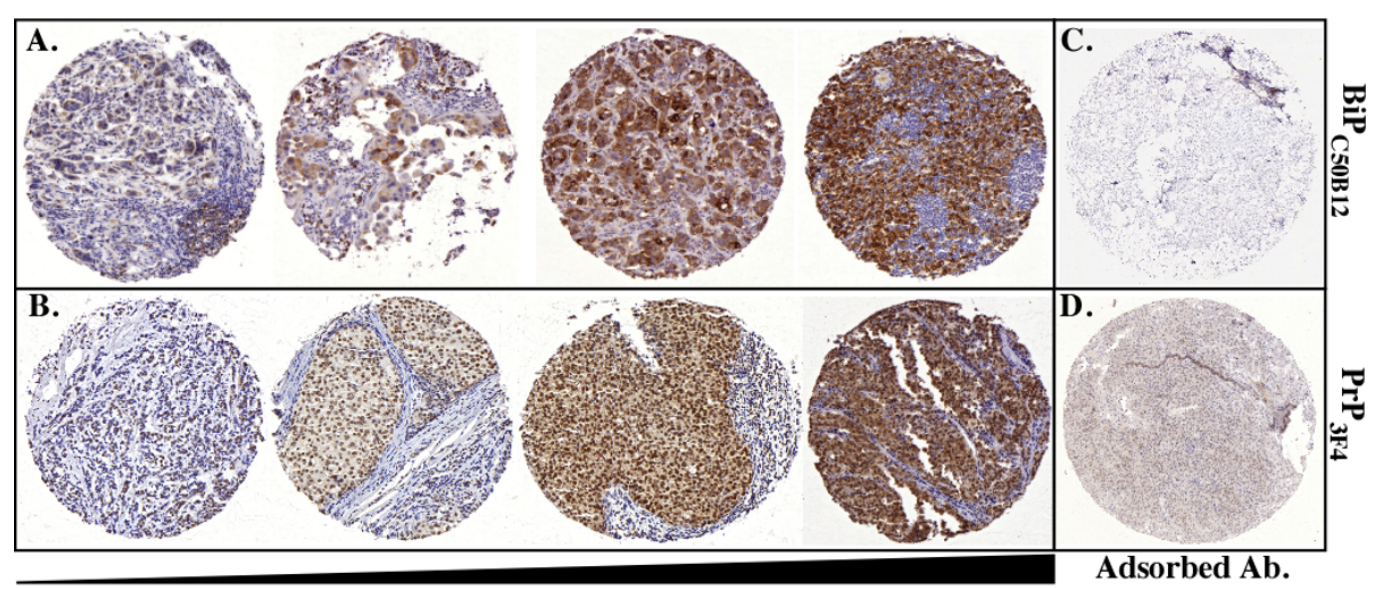

Examples of immunohistochemical staining with increasing intensity

E.

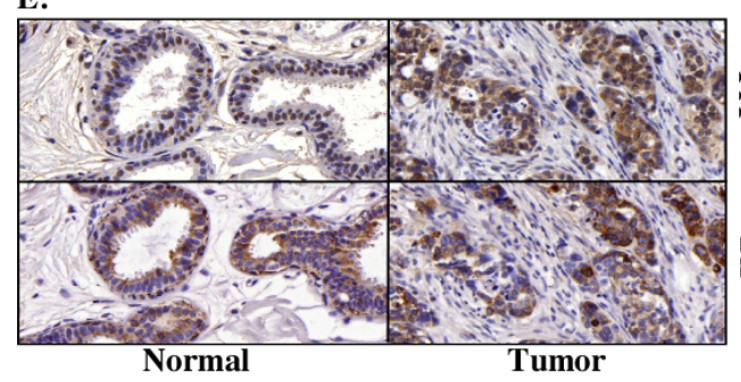

G.

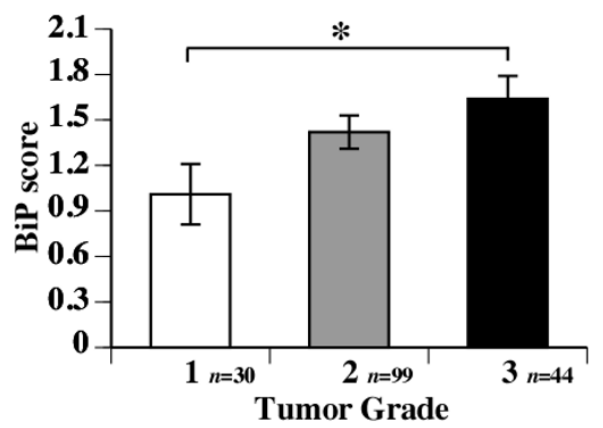

I.

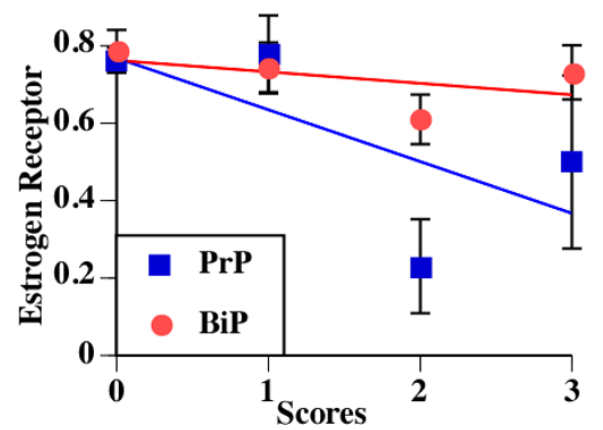

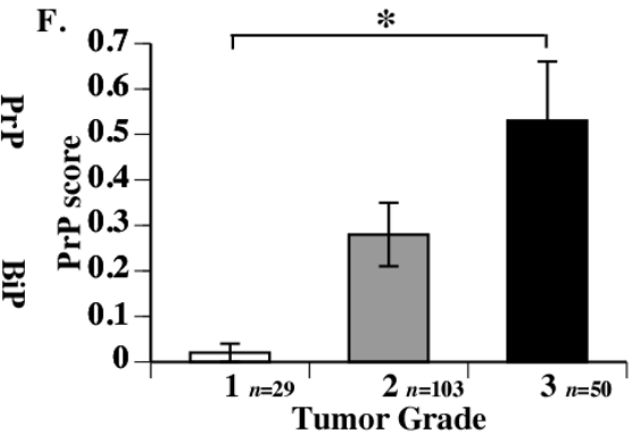

H.
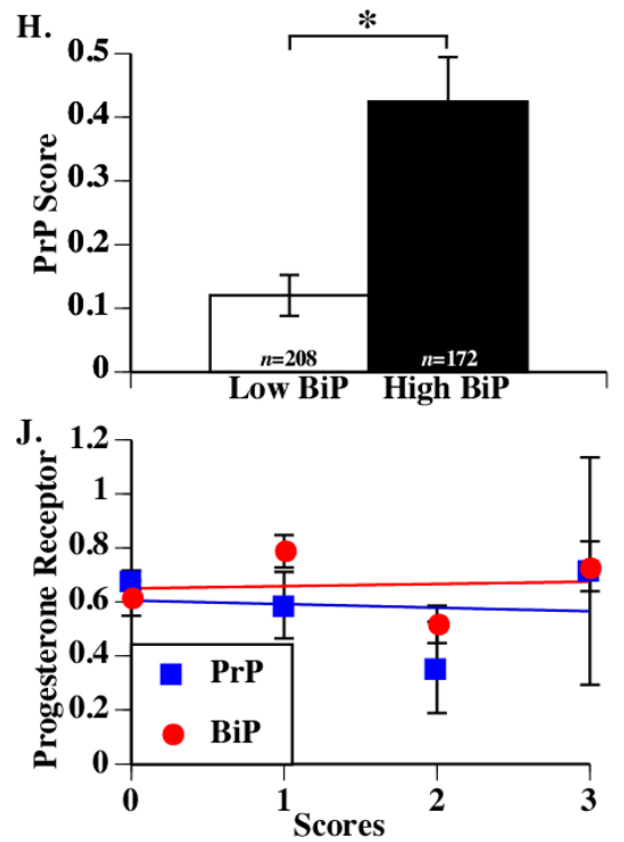

Figure 2 PrP levels are significantly higher in high BiP-expressing breast cancer tumors. Representative micrographs of breast tissue cores immunostained for BiP (C50B12) (A) or PrP (3F4) (B), adsorption control for BiP (C) and PrP (D). E shows staining of PrP and BiP in normal versus tumor tissue cores. Mean intensity score (mean \pm SEM) of $\operatorname{PrP}(\mathbf{F})$ or BiP $(\mathbf{G})$ immunostaining correlated with tumor grade. $\mathbf{H}$. Comparison of the mean intensity score (mean \pm SEM) of PrP immunostaining in breast tissue cores showing Low (0 to 1$)$ or High BiP (2 to 3 ) immunostaining scores. Correlation between averaged estrogen $(\mathbf{I})$ and progesterone $(\boldsymbol{J})$ receptor levels in cores (ERS/PR positive $=1$ and ERS/PR negative $=0$ ) correlated with PrP scores. Correlations were done with Spearman's rank correlation in InStat. ERS versus PrP: $r=-0.2036, p=0.0025$, PR vs PrP: $r=-0.2277, P=0.0007$, ERS vs BiP: $r=-0.08819, P=0.2108$, and PR vs BiP $r=-0.04398, p=0.5353$. 
Table 2 Association between high BiP mRNA levels and PrP mRNA levels

\begin{tabular}{|c|c|c|c|c|c|c|}
\hline & & $\begin{array}{c}\text { Low BiP } \\
\text { Mean } \pm \text { SD }\end{array}$ & $\begin{array}{c}\text { High BiP } \\
\text { Mean } \pm \text { SD }\end{array}$ & $\begin{array}{c}P- \\
\text { value }\end{array}$ & $n$ & Reference \\
\hline & $\mathrm{BiP}$ & $0.80 \pm 0.1$ & $1.29 \pm 0.3$ & $\leq 0.001^{*}$ & 127 & van der Vijver et al., 2002 \\
\hline & PrP & $1.01 \pm 0.5$ & $1.24 \pm 0.7$ & $0.002^{*}$ & & \\
\hline \multirow[t]{4}{*}{ Breast cancer } & $\mathrm{BiP}$ & $0.78 \pm 0.1$ & $1.26 \pm 0.3$ & $\leq 0.001^{*}$ & 44 & Minn et al., 2005 \\
\hline & PrP & $0.93 \pm 0.4$ & $1.09 \pm 0.5$ & 0.1 & & \\
\hline & $\mathrm{BiP}$ & $0.76 \pm 0.2$ & $1.43 \pm 0.4$ & $\leq 0.001^{*}$ & 40 & Chin et al., 2006 \\
\hline & PrP & $1.00 \pm 0.5$ & $1.38 \pm 0.6$ & $0.003^{*}$ & & \\
\hline Breast carcinoma & $\mathrm{BiP}$ & $0.77 \pm 0.2$ & $1.37 \pm 0.4$ & $\leq 0.001^{*}$ & 56 & Neve et al., 2006 \\
\hline cell lines & PrP & $0.99 \pm 0.9$ & $1.94 \pm 1.0$ & $0.001^{*}$ & & \\
\hline
\end{tabular}

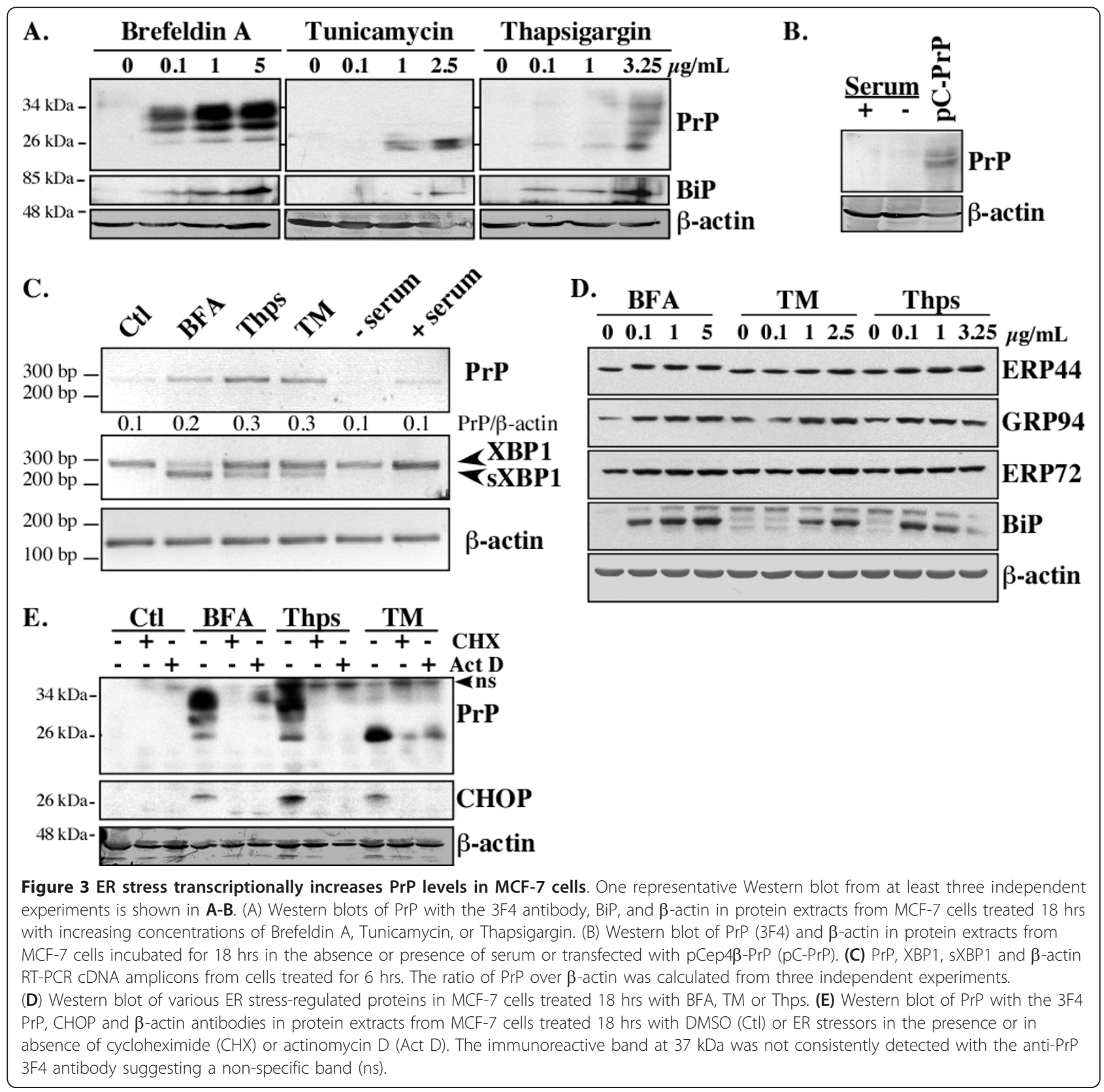




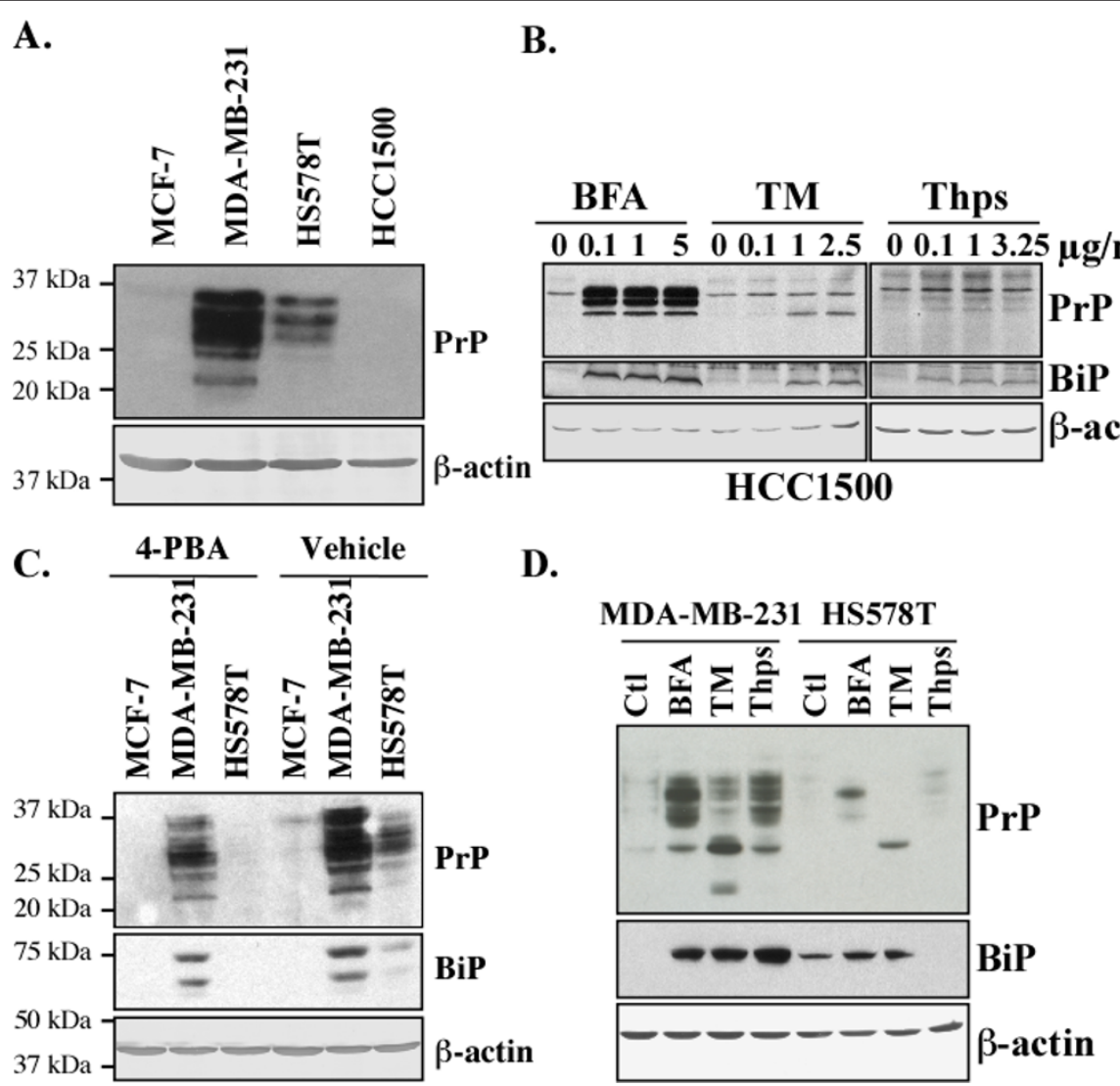

Figure 4 ER stress increases PrP levels in MDA-MB-231, HS578T and HCC1500 cell lines. Western blot of (A) PrP in protein extracts of MCF-7, MDA-MB-231, HS578T and HCC1500 cell lines, (B) PrP and BiP in protein extracts from HCC1500 cells treated with BFA, TM or Thps, (C) PrP and BiP in protein extracts from MCF-7, MDA-MB-231 and HS578T cell lines treated with 4-PBA or vehicle, (D) PrP and BiP in protein extracts of MDA-MB-231 and HS578T cell lines treated with BFA, TM and Thps. $\beta$-actin was probed as a loading control.

$[35,42,43,57]$ and may be explained by the presence of transcriptional motifs overlapping the ERSE as indicated in Figure 4C. Alternatively, the mutations affect the structure of the promoter rendering it less responsive to transcriptional factors. Cells treated with BFA lost their ability to significantly induce luciferase activity in the PRNP ERSE mutants (Figure 5E). The ERSE-like and ERSEb mutations abolished the induction of luciferase activity in Thps-treated cells, while it was retained in the ERSEa and ERSE-II mutants. TM induced luciferase activity in the cells transfected with wild type or mutant ERSE-like, ERSEa and ERSEb PRNP promoter but not in the ERSE-II mutant. The four ERSE motifs of the human PRNP promoter are well conserved among primates (Figure 5F), but not well conserved in other mammalian species. Only the ERSE-like is highly conserved in the mouse, rat or hamster Prnp promoters.

Taken together, these results indicate that (a) the PRNP promoter ERSE motif sequences overlap with those regulating the basal expression of PRNP, (b) the ERSE motifs positively regulate ER stress-mediated transcription of the PRNP gene, (c) the PRNP promoter is differentially regulated with the three different ER stresses, and (d) ER stress-mediated regulation of $P R N P$ gene expression may have evolved in primates but not in other mammalian species.

\section{Role of ATF6 $\alpha$ and XBP1 in ER stress-mediated PRNP gene expression}

To determine which transcription factor regulates ER stress-mediated PRNP gene expression in MCF-7 cells, we investigated $\triangle \mathrm{ATF} 6 \alpha, \mathrm{sXBP} 1$ and phosphorylation of eIF2 $\alpha$ (peIF2 $\alpha$ ), as markers of the three UPR response pathways, and compared these to PrP levels. Because the ATF4 motif is absent in the PRNP promoter, we focused on $\triangle$ ATF $6 \alpha$ and sXBP1. In MCF-7 cells, $\triangle$ ATF6 $\alpha$ and peIF $2 \alpha$ appeared within 30 minutes, sXBP1 increased between one to two hours, and PrP levels increased within one hour of BFA treatment (Figure 6A). With Thps, truncated ATF6 $\alpha$ increased at three hours, peIF2 $\alpha$ and sXBP1 increased within 30 minutes, and PrP levels increased at six hours of treatment. TM induced truncated ATF $6 \alpha$ 

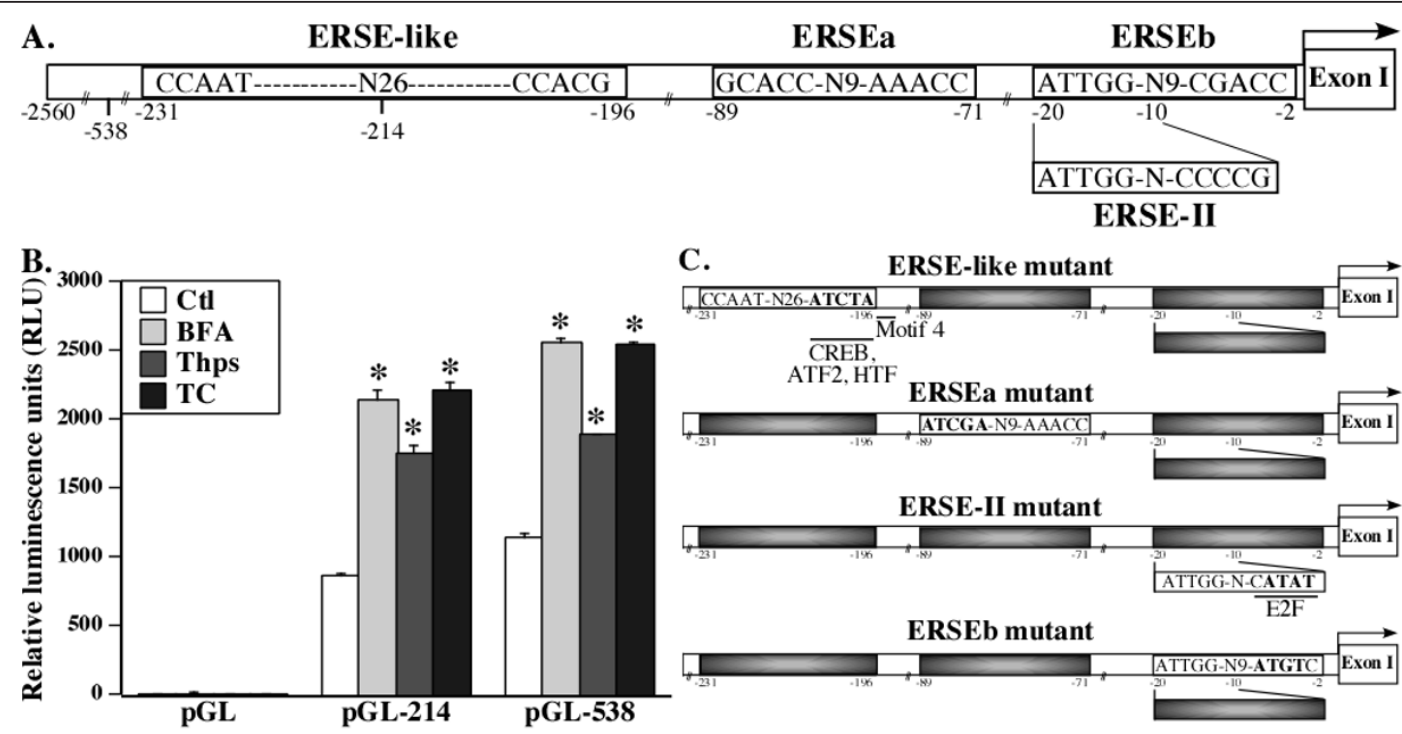

C. ERSE-like mutant
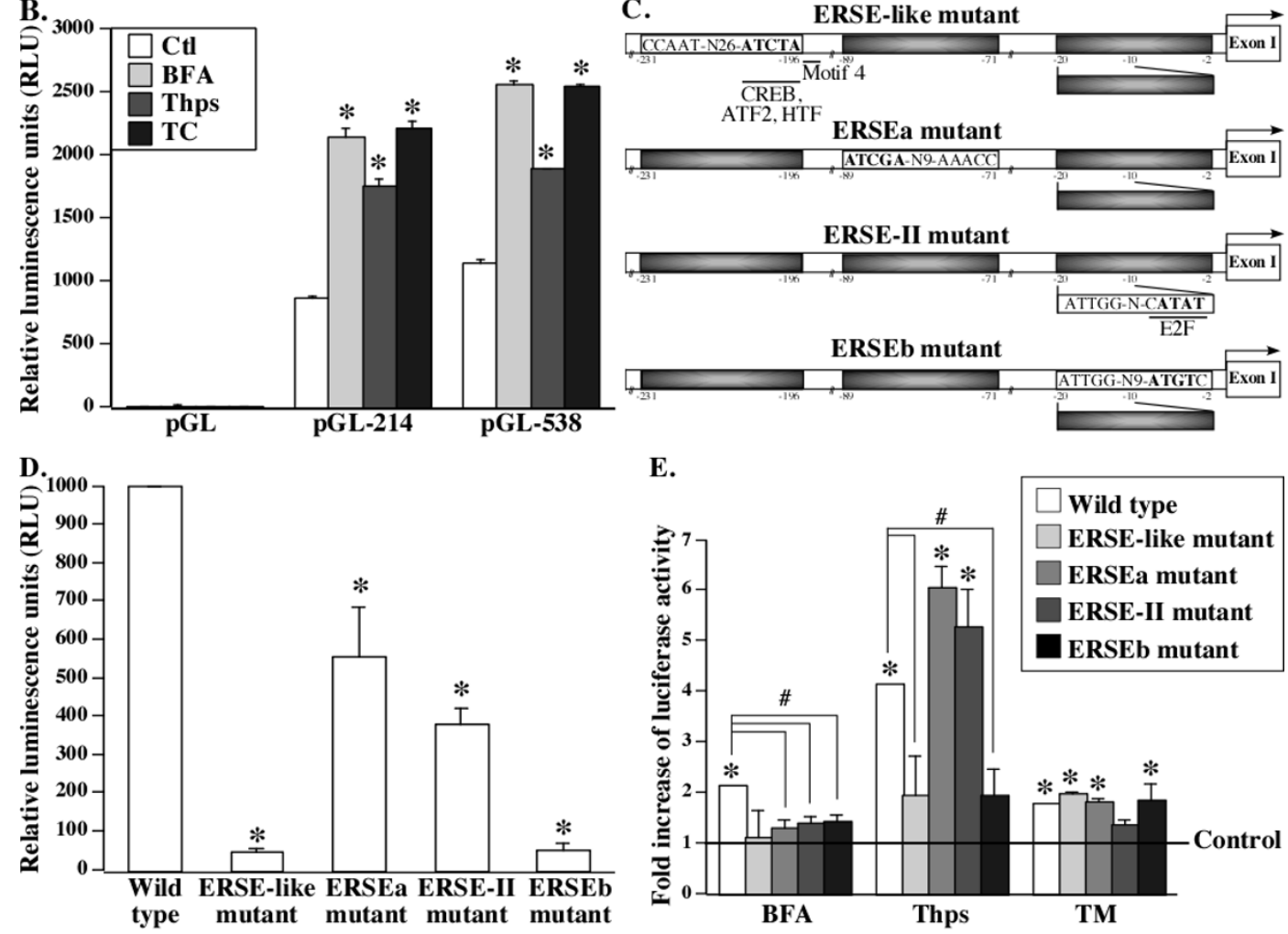

F.

\begin{tabular}{|c|c|c|c|}
\hline Human & 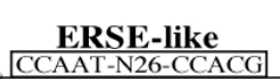 & $\begin{array}{c}\text { ERSEa } \\
\text { GCACC-N9-AAACC }\end{array}$ & \begin{tabular}{|c|} 
ERSE-II \\
ATTGG-N-CCCCG-N3-CGACC \\
\end{tabular} \\
\hline Chimpanz & $\begin{array}{l}-196 \\
\text { CCAAT-N26-CCACG } \\
\end{array}$ & GCACC-N9-AAACC & $\frac{10}{20}$ \\
\hline Gorilla & CCAAT-N26-CCACG & GCACC-N9-AAACC & ATTGG-N-CCCCGI-N3-CGACC \\
\hline Orangutai & CCAAT-N26-CCACG & GCACC-N9-AAACC & \begin{tabular}{|l|l|} 
ATTGG-N-CCCCGI-N3-CGACC \\
\end{tabular} \\
\hline Macaque & CCAAT-N26-CCACG & GCACC-N9-AAACC & \begin{tabular}{|l|l|} 
ATTGG-N-CCCCGIS3-CGACC \\
\end{tabular} \\
\hline Mouse & CCATT-N25-CGTCG & CG*GG-N9-A***** & *** ${ }^{*} *-\mathrm{N}^{*}{ }^{*} \mathrm{CC}{ }^{*} \mathrm{C} \mid \mathrm{N} 3-\mathrm{CG}{ }^{*} \mathrm{C} *$ \\
\hline 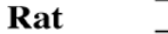 & CCATT-N25-CGTCG & $* \mathrm{GA}^{*} \mathrm{G}-\mathrm{N} 9-\mathrm{A} * * * *$ & \begin{tabular}{|l|l|l|l} 
** $\mathrm{C} * \mathrm{~N}-* \mathrm{CC} * \mathrm{C} \mid \mathrm{N} 3-\mathrm{CC} * \mathrm{C} *$ \\
\end{tabular} \\
\hline & CCATT-N25-CG*CG & CG*GG-N9-A***C & 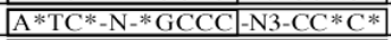 \\
\hline & CC*TT-N26-C*A*** & XXXXX-N9-AAACC & XXXXX-N-XXXXX-N3-XXXXX \\
\hline & CC*T*-N26-C*A** & XXXXX-N9-AAACC & XXXXX-N-XXXXX-N3-XXXXX \\
\hline
\end{tabular}

Figure 5 Identification of ER stress response elements (ERSE) in the PRNP promoter. (A) Schematic diagram of two ERSE (ERSEa and ERSEb), one ERSE-like, and one ERSE-II in the human PRNP promoter. (B) Luciferase activity in HEK293T cells transfected with pGL2 (empty vector), pGL-214 (vector containing the first 214 nucleotides of human PRNP promoter), or PGL-538 (first 538 nucleotides of human PRNP promoter) and treated six hours with ER stressors. Data are expressed as the mean \pm SD of two experiments done in triplicate. ${ }^{*}$ Indicates $P$ $\leq 0.05$ compared to the control $(\mathrm{Ctl})$. (C) Schematic diagram of the PRNP promoter mutants showing the mutated nucleotides in bold. Putative transcription factor binding sites predicted by TRANSFAC and the conserved motif 4 affected by the mutations are shown. (D) Luciferase activity measured in HEK293T cells transfected with wild type PRNP promoter (pGL-538) or ERSE mutants of the PRNP promoter. Data represent the mean \pm SEM of three experiments done in triplicate. ${ }^{*}$ Indicates $P \leq 0.05$ compared to wild type. (E) Luciferase activity in HEK293T cells transfected with wild type or ERSE mutant PRNP promoters and treated with DMSO (control) or ER stressors. The fold increase of luciferase activity calculated for each PRNP promoter construct corresponds to the ratio of the RLU in presence of ER stress over the RLU in presence of DMSO (Control). Data represent the mean \pm SEM of three independent experiments done in triplicate. ${ }^{*}$ Indicates $P \leq 0.05$ compared to the control (DMSO) and \# indicates $P \leq 0.05$ between the mutants and the wild type PRNP promoter. (F) Schematic diagram showing conservation of human ERSE-like, ERSEa, ERSE-II and ERSEb. Nucleotide sequence alignment of PRNP promoters is from a previous study [48] and from an alignment done with Ensembl databases. $\mathrm{N}$ indicates the number of nucleotide. Compared to human PRNP promoter, ${ }^{*}$ indicates a nonconserved and non-complementary nucleotide while $\mathrm{X}$ denotes an absent nucleotide. 


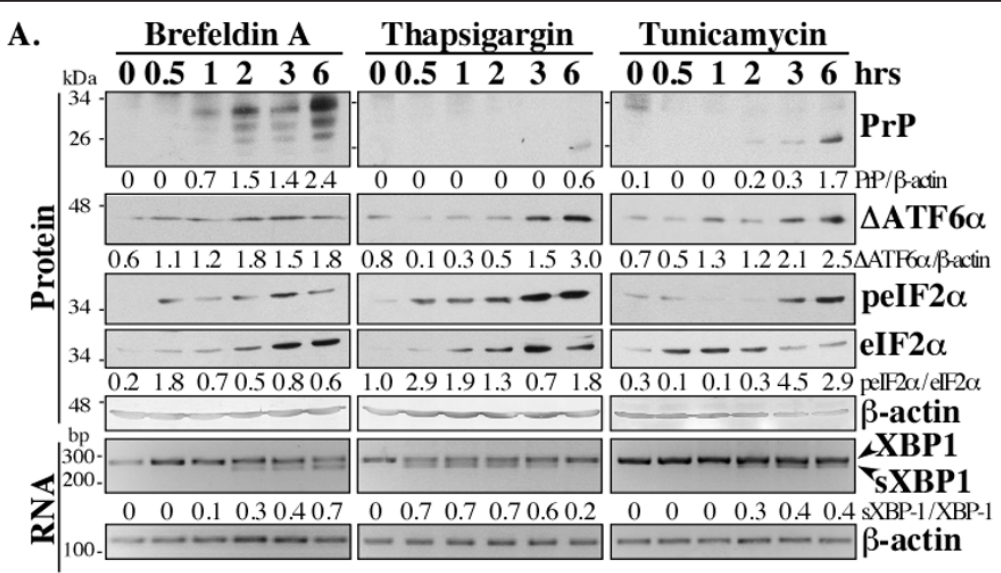

B.
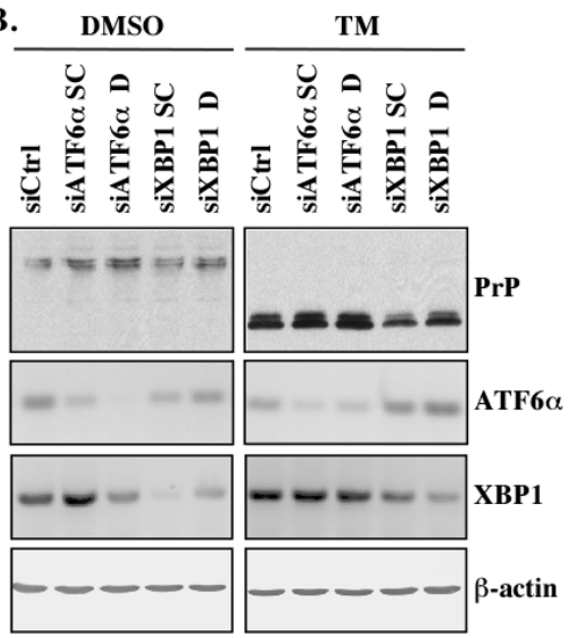

E.

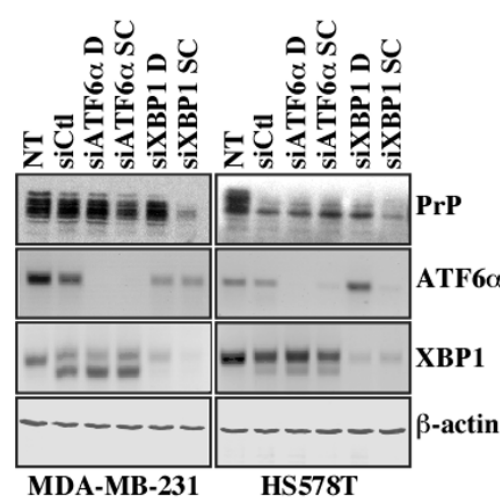

C.

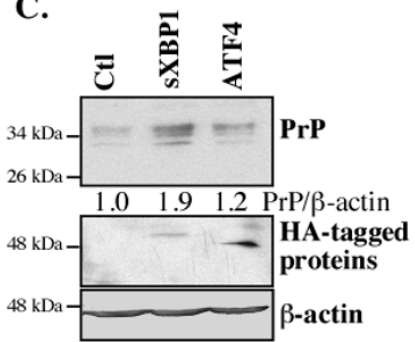

D.
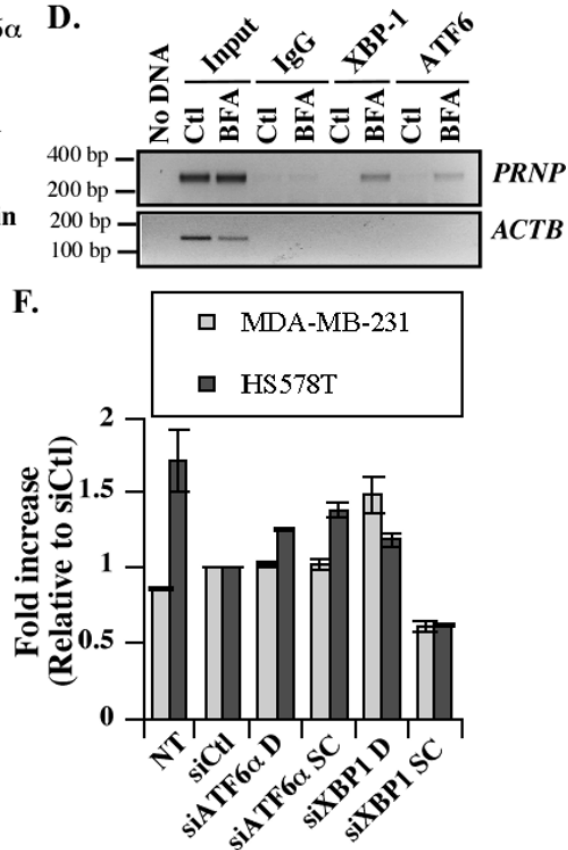

Figure 6 sXBP1 is involved in PRNP gene expression in MCF-7 and MDA-MB-231 cells. (A) Western blot analyses of PrP with the 3F4 antibody, cleaved ATF6 $\alpha(\triangle A T F 6 \alpha$ ), phosphorylated elF2 $\alpha$ (pelF2 $\alpha$ ), total elF2 $\alpha$, and $\beta$-actin. Lower panels represent XBP1, spliced XBP1 (sXBP1) and $\beta$-actin amplified by RT-PCR. Protein or mRNA extracts were from MCF-7 cells treated with ER stressors for 0 to 6 hrs. The increase of PrP and $\triangle A T F 6 \alpha$ levels compared to $\beta$-actin levels and the ratios of pelF $2 \alpha /$ elF $2 \alpha$ and sXBP1/XBP1 are indicated. (B) MCF-7 cells transfected with siATF6 $\alpha$ or siXBP1 and proteins immunoblotted with 3F4 PrP and $\beta$-actin antibodies. RT-PCR shows levels of ATF $6 \alpha$ and XBP1 mRNAs. (C) Western blot analyses of PrP, HA tag and $\beta$-actin in protein extracts from MCF-7 cells transfected for 6 hrs with pCGN-IRES-EGFP (Ctl), pCGNHA-sXBP1-IRES-EGFP, and pCGN-HA-ATF4-IRES-EGFP constructs. (D) ChIP assays performed on DMSO (Ctl)- or BFA-treated MCF-7 cells with IgG control, XBP1 or ATF6 $\alpha$ antibodies. PCR amplification of PRNP and $\beta$-actin gene promoters (ACTB) was done on immunoprecipitated and nonimmunoprecipitated (input) DNA. (E) Western blot of PrP (top panel) and $\beta$-actin (bottom panel) and ethidium stained agarose gel containing ATF6 $\alpha$ and XBP1 amplicons from MDA-MB-231 or HS578T cells transfected with siCtl, siATF6 $\alpha$ or siXBP1. NT indicates non-transfected, D indicates the Dharmacon siRNAs and SC indicates the Santa Cruz siRNAs. (F) Levels of PRNP mRNA detected by qRT-PCR in siATF6 $\alpha$ or siXBP1transfected cells. 
within one hour, peIF $2 \alpha$ within three hours, and sXBP1 and PrP within two to three hours. Variation in total eIF2 $\alpha$ levels was observed under the three ER stressors, as previously reported $[58,59]$, while $\beta$-actin mRNA and protein levels remained relatively constant. These results indicate that all three UPR response pathways are activated before ER stress-mediated PrP up-regulation in MCF-7 cells.

Silencing ATF6 $\alpha$ with two different siRNAs did not alter TM-mediated increased levels of PrP (Figure 6B). However, knock down (KD) of XBP1 in MCF-7 cells, considerably stunted the TM-mediated increase in PrP. Over-expression of HA-tagged SXBP1 increased PrP levels above low levels observed in cells transfected with the control pCGN-IRES-EGFP vector, while HA-tagged ATF4 did not modulate PrP levels (Figure 6C). Using chromatin immunoprecipitation (ChIP) assays, we further showed that both XBP1 and ATF6 $\alpha$ bound to the PRNP promoter in BFA-treated MCF-7 cells (Figure 6D). In contrast, neither interacted with the $\beta$-actin $A C T B$ promoter. These results show that SXBP1 in MCF-7 cells is involved in transactivating PRNP gene expression, whereas ATF6 $\alpha$ can interact with, but does not transactivate $P R N P$.

To determine if PRNP gene expression in the basal carcinoma cell lines depends on ER stress, we knocked down (KD) ATF6 $\alpha$ and XBP1 with siRNAs in the MDA-MB-231 and HS578T cell lines (Figure 6E). In the MDA-MB-231 cell line, two different siRNAs to ATF6 $\alpha$ and XBP1 efficiently decreased the levels of ATF $6 \alpha$ and sXBP1, respectively (Figure 6E). The level of $\operatorname{PrP}$ (Figure 6E) and PRNP mRNA (Figure 6F) were not decreased by the ATF6 $\alpha$ KD. However, the siCtl and siATF6 $\alpha$ produced an unexpected increase in SXBP1 in MDA-MB-231 cells, which could obscure the effect of siATF6 $\alpha$ on PRNP gene expression. Indeed, an almost complete XBP1 KD with siXBP1 SC decreased PrP and PRNP mRNA levels by $40 \%$, whereas a partial siXBP1 D KD did not decrease PRNP gene expression at either the protein or mRNA level (Figure 6E, F). Both pairs of siRNAs against ATF $6 \alpha$ and XBP1 were highly efficient in the HS578T cell line and the siCtl or siATF $6 \alpha$ had much less effect on the levels of sXBP1 (Figure 6E). The levels of PrP assessed by Western blotting decreased relative to the non-transfected cells but not necessarily relative to the siCtl, except for the siATF6 $\alpha$ SC (Figure 6E). Furthermore, qRT-PCR results showed that the levels of PrP mRNA decreased by $40 \%$ only with the siXBP1 SC (Figure 6F). The discrepancy between the effect of these two different siXBP1s is unclear. Both decrease XBP1 mRNA levels similarly so we must assume that one of these has off-target effects that differentially regulate PRNP gene expression. These results indicate that the ATF6 $\alpha$ is not regulating PRNP gene expression in MDA-
MB-231 or HS578T cell lines, while XBP1 is possibly implicated in the MDA-MB-231 cell line.

\section{sXBP1 and $\triangle \mathrm{ATF} 6 \alpha$ regulate luciferase activity from the pGL-538 PRNP promoter in HEK293 cells}

To more directly assess if sXBP1 and $\triangle \mathrm{ATF} 6 \alpha$ transactivate PRNP gene expression from its promoter, HEK293 cells were co-transfected with pCGN constructs encoding sXBP1 or $\triangle \mathrm{ATF} 6 \alpha$ and the pGL-538 PRNP promoter luciferase reporter construct. Overexpression of both $\triangle \mathrm{ATF} 6 \alpha$ and sXBP1 was confirmed by RT-PCR (Figure 7A) and both of these transcription factors transactivated luciferase expression from the pGL-538 PRNP promoter luciferase reporter construct (Figure 7B). Furthermore, KD of ATF6 $\alpha$ and XBP1 expression with two different siRNAs (Figure 7C), prevented Thps-induced luciferase expression from the pGL-538 construct (Figure 7D). The siATF6 $\alpha$ SC siRNA induced an overall increase in luciferase activity compared to the siCtl but the levels did not differ between DMSO and Thps. This suggests that this siRNA may induce other transcription factors that up-regulate PRNP gene expression. Taken together, these results confirm that both ATF6 $\alpha$ and sXBP1 can up-regulate PRNP gene expression in HEK293 cells.

\section{PrP delays ER stress-mediated cell death}

One way PrP could favor cancer progression is by opposing cell death. Because the cellular form of PrP has antiapoptotic activity, we investigated if $\operatorname{PrP}$ up-regulation could participate in the UPR pro-survival response. Compared to control siRNA, PrP silencing increased the percentage of cells displaying pan-caspase activity (Figure 8A) and condensed chromatin (Figure 8B) in MCF-7 cells treated with BFA, Thps or TM. A similar vulnerability against ER stressors was observed in hippocampal Prnp null cells (Figure 8C, E). Furthermore, siRNA KD of PrP increased the levels of pan-caspase activity in MDA-MB-231 cells treated with the three ER stressors, indicating a protection by $\operatorname{PrP}$ in this basal cell line (Figure 8E). However, we did not observe higher caspase activity in the HS578T cell line, except in the $10 \mu \mathrm{g} / \mathrm{ml}$ Thps condition (Figure 8F). This result indicates that different cell lines require different doses of ER stress for induction of cell death. Nevertheless, the results indicate that PrP delays ER stress-induced cell death in MCF-7 and in MDA-MB-231 cells.

\section{PrP does not prevent ER stress-mediated Bax activation in MCF-7 cells}

We have previously discovered that PrP can inhibit Baxmediated cell death $[2,4]$. Immunoprecipitation of the pro-apoptotic 6A7-immunoreactive form of Bax indicated that BFA, TM and Thps all induce Bax activation 
A.

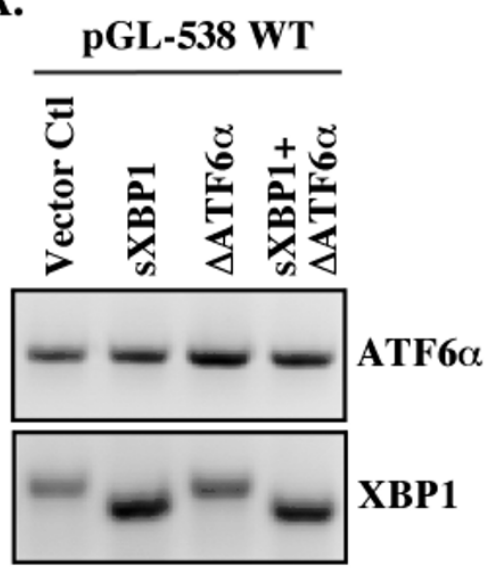

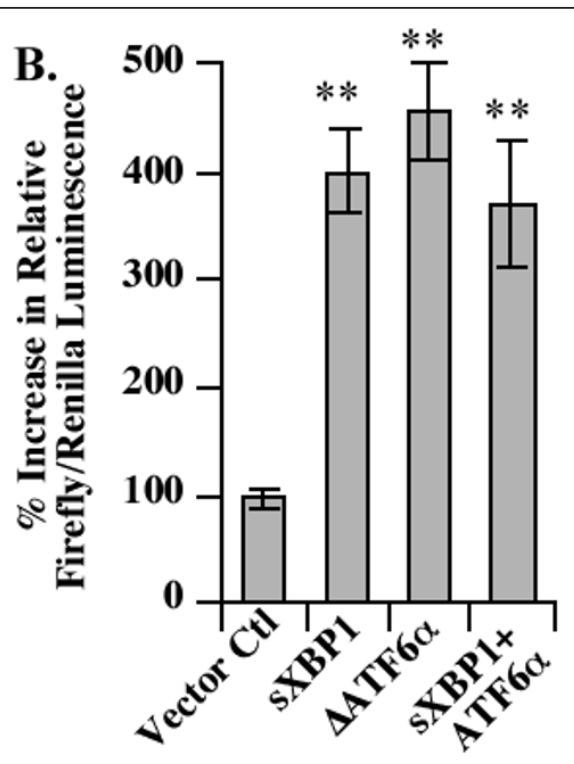

C.

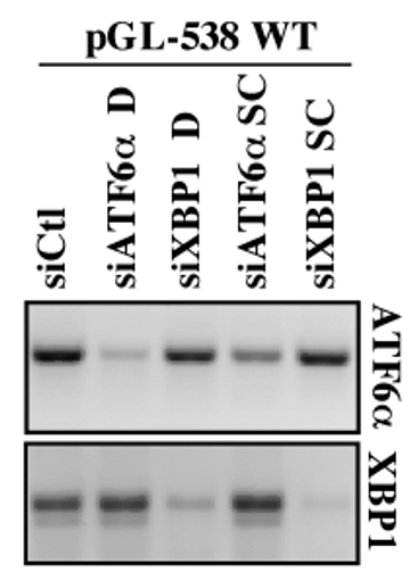

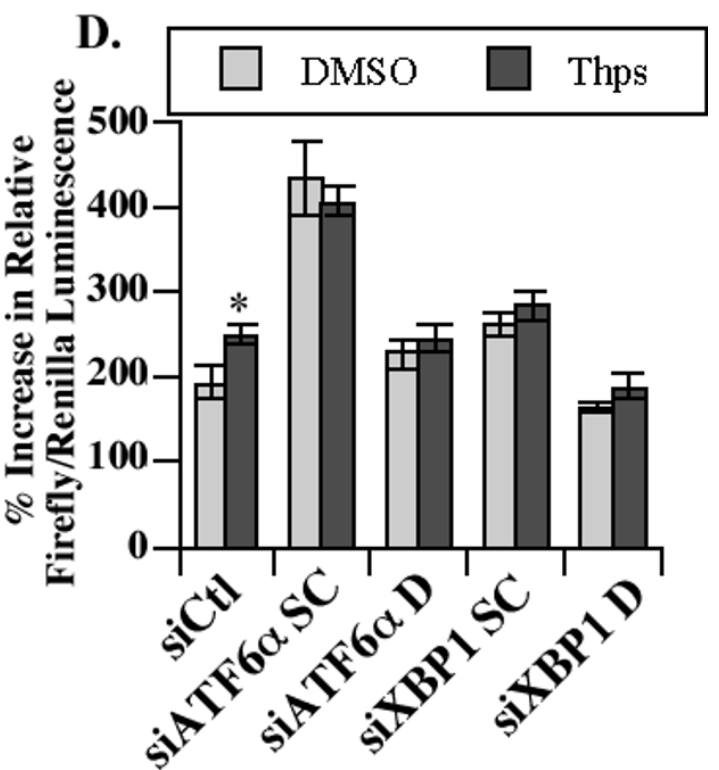

Figure 7 ATF6 $\alpha$ and XBP1 transactivate PRNP promoter. (A) Ethidium bromide stained gel showing $\triangle A T F 6 \alpha$, sXBP1 and XBP1 amplicons from HEK293 cells co-transfected with the pGL-538 PRNP promoter luciferase reporter and pCGN-ATF6 $\alpha$ (1-373) and/or pCGN-sXBP1.

(B) Luciferase luminescence generated from HEK293 cells co-transfected as described in A. (C) Ethidium bromide stained gel showing ATF6 $\alpha$ and XBP1 amplicons from HEK293 cells co-transfected with the PGL-538 PRNP promoter luciferase reporter and siRNAs against ATF6 $\alpha$ or XBP1.

(D) Luciferase luminescence generated from HEK293 cells co-transfected as described in C. Statistical analyses on B and D were one-way ANOVA followed by a Tukey-Kramer multiple comparison test.

(Figure 9A-C). However, silencing PrP before ER stress did not increase the level of Bax activation indicating that PrP cannot prevent ER stress-induced Bax activation and that PrP delays ER stress-mediated cell death by another mechanism.

ER stress with BFA, TM or Thps was confirmed by up-regulation of $\mathrm{BiP}$ levels in the presence or absence of PrP KD (Figure 9A-C). ER stress is known to induce CHOP during apoptosis and CHOP transcriptionally increases pro-apoptotic protein, Bim [60]. Bim was increased in Thps-treated MCF-7 cells (Figure 9C), but not in BFA or TM-treated cells (Figure 9A, B). Again, siRNA inhibition of ER stress-mediated PrP gene expression did not alter Bim levels. Bcl-2 levels were also constant in ER stress-treated cells with or without PrP silencing with siRNAs. We repeated these experiments with another siRNA against PrP and observed identical results (Figure 9D). Therefore, it is unlikely 


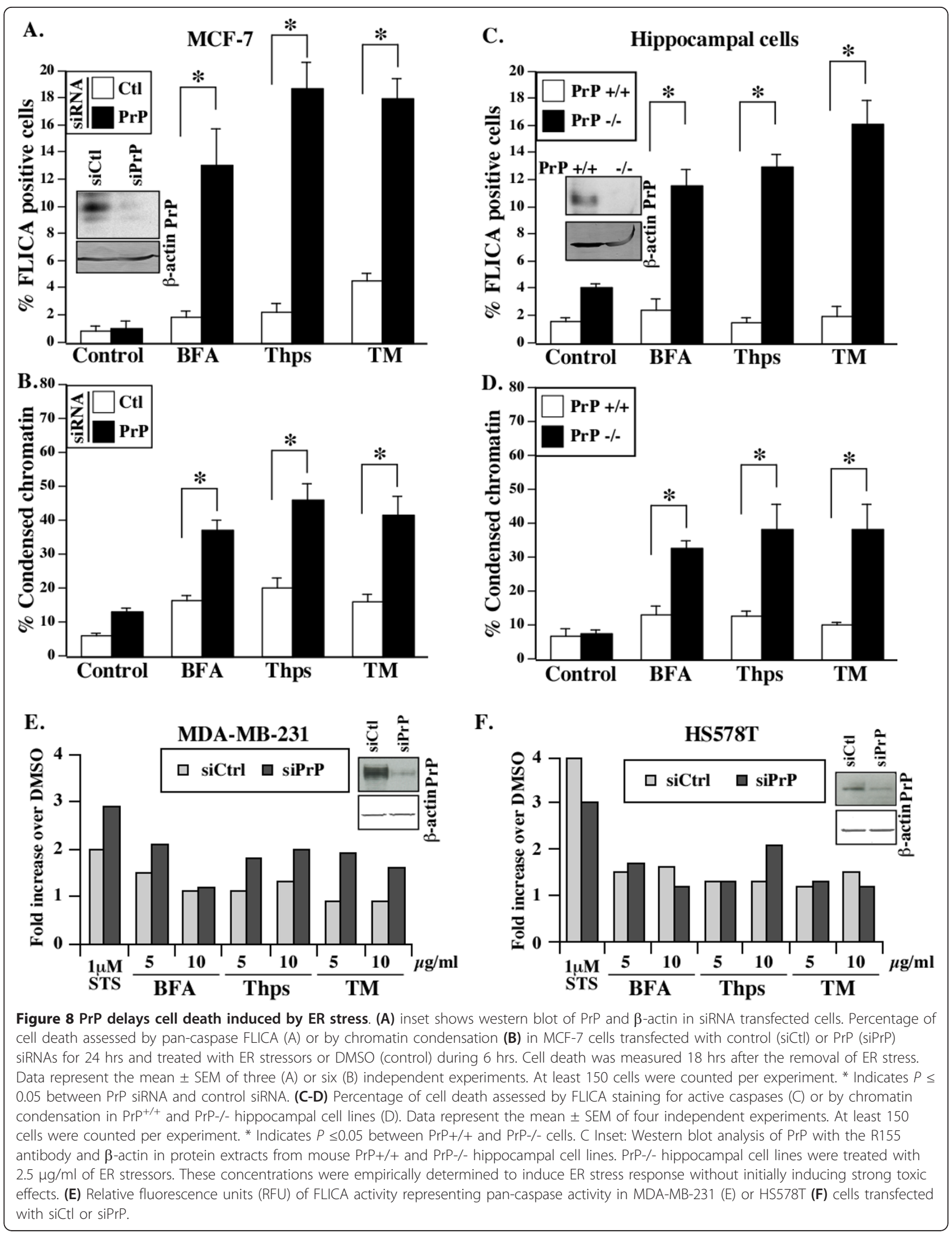




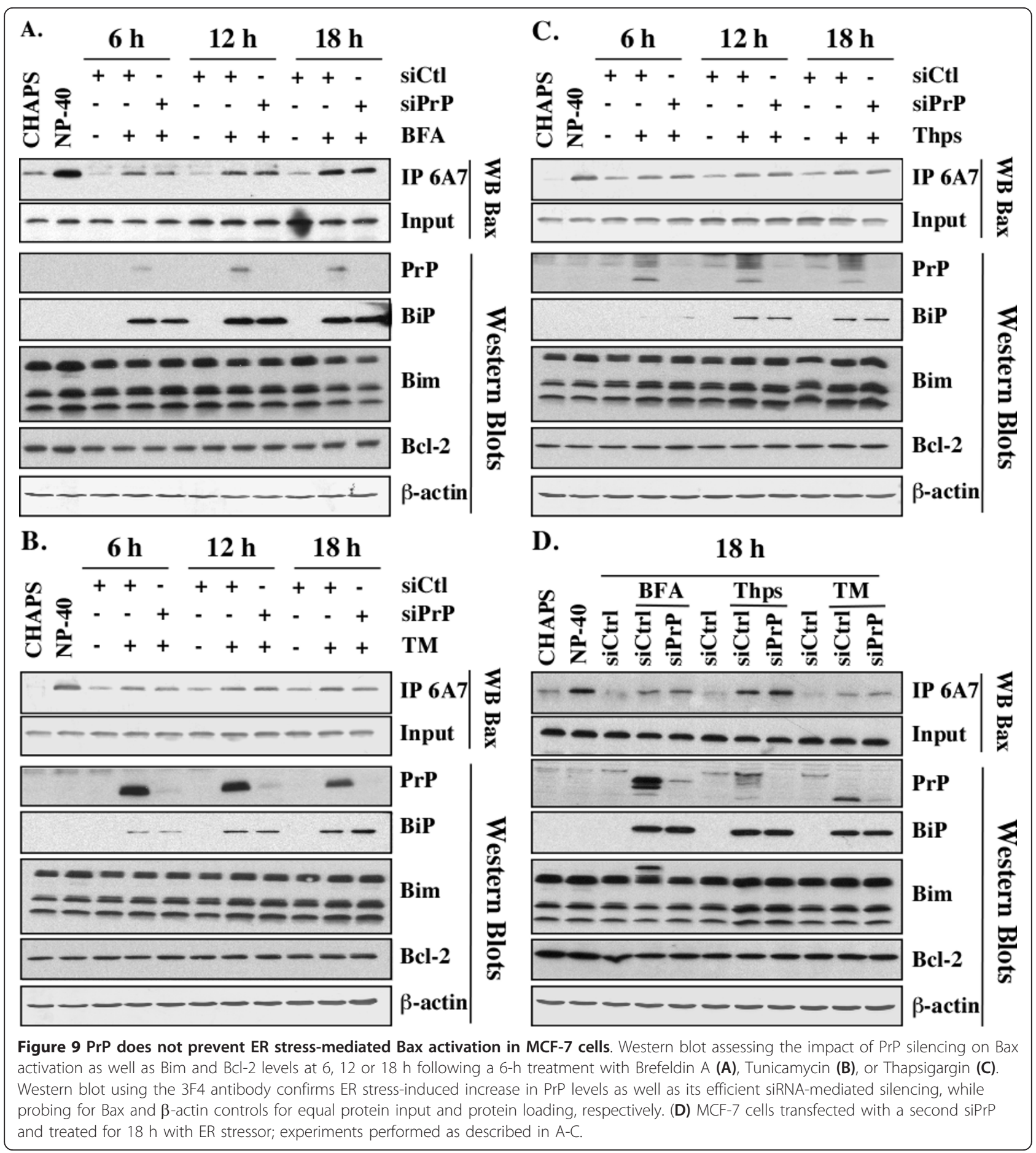

that PrP protects against ER-mediated cell death by targeting members of the Bcl-2 family of proteins.

\section{Discussion}

In the present manuscript, we show that (1) human PRNP gene expression is up-regulated by ER stress, (2) that the UPR-activated sXBP1 and $\triangle \mathrm{ATF} 6 \alpha$ are involved in transcriptional activation of PRNP, (3) that PrP protects against ER stress-mediated cell death, and (4) that PrP may contribute to increased survival of breast cancers.

Our first observation in this study was that PRNP gene expression is regulated by ER stress in both basal and luminal breast cancer cell lines. Indeed, three different ER 
stressors increase the levels of PrP in MCF-7 cells and in the MDA-MB-231, HS578T and HCC1500 breast carcinoma cell lines. The MDA-MB-231 and HS578T cell lines have intrinsic ER stress activity based on higher levels of ER stress-regulated $\mathrm{BiP}$ and correspondingly have much higher PrP levels than the MCF-7 and HCC1500 cell lines. Furthermore, the ER stress inhibitor, 4-PBA, decreases both BiP and PrP in MDA-MB-231 and HS578T cell lines. While the overexpression of PrP definitely has a negative impact on several types of cancers, surprisingly little is known about the regulation of PRNP gene expression. Human PRNP is localized on chromosome 20 and contains a short un-translated exon I separated from the coding exon II by a $13 \mathrm{~kb}$ intron [48,61-63]. PRNP has one major transcriptional start site and its promoter contains a CCAAT box, a high G/C content, and an SP1 transcription factor binding site characteristic of constitutively expressed genes. It also contains several putative conditionally activated transcriptional binding sites: developmentally-regulated GATA, AP-2, Nkx2-5 and Myo D, signal-dependent p53 and HSE, cell membrane receptordependent AP1, immune-mediated nuclear factor IL-6, NF-AT and Ets-1, and metal responsive element binding sites $[48,62,64]$. These transcriptional binding site sequences are located in two clusters, one within exon I, and the other in the 800 nucleotides upstream of the start site. Of these, only Sp1, metal transcription factor-1 (MTF-1), HSE and p53 recently have been confirmed to regulate human PRNP or mouse Prnp gene expression [21,64-66]. In addition, four motifs with unknown function are highly conserved among mammalian PRNP promoters $[48,67]$. Our finding that ER stress can up-regulate PRNP gene expression has certain implications in cancer because cancers are ER stressed [68] and PrP has been reported to have protective functions that appear to be involved in the resistance of cancers to chemotherapy [12-14,69].

Our second observation is that the up-regulation of $\operatorname{PrP}$ occurs through transactivation of the PRNP gene. We describe four ERSE in the promoter of PRNP, which respond to the three pharmacological ER stressors, BFA, Thps and TM. Mutagenesis of these ERSE dampens the ER stress-mediated up-regulation of PRNP. In addition, $\triangle \mathrm{ATF} 6 \alpha$ and sXBP1 directly increase expression from the PRNP promoter and siRNAs against either ATF6 $\alpha$ or XBP1 prevents Thps-mediated PRNP gene expression. Furthermore, ChIP analyses shows that both XBP1 and ATF6 $\alpha$ interact with the PRNP promoter. In MCF-7 cells, the three pharmacological ER stressors increase ATF $6 \alpha$ and sXBP1 but only the KD of XBP1 prevents ER stressmediated up-regulation of PRNP gene expression. A similar effect is observed in MDA-MB-231 cells but not in the HS578T cell line. These results suggest that PRNP gene expression can be regulated by both ATF6 $\alpha$ and XBP1, but that the regulation is complex and depends on the cellular context. Together, these results add ER stress as an important human regulator of PRNP gene expression.

Interestingly, the ERSE elements are specific to primate PRNP promoters since three of the ERSE elements are quite degenerate in rodents and ovines while the remaining ERSE is conserved in rodents but not in ovines. In addition, $P R N P$ gene expression is differentially regulated by each of the three ER stressors. The presence of these ERSE in the primate PRNP promoter and the differential regulation by ER stressors suggests that the regulation of PRNP gene expression is highly complex in primates and is consistent with the reported inability of ER stress to increase PrP levels in murine cells [70-72]. It must, therefore, be noted that ER stress regulation of Prnp gene expression would remain undetected in mouse models of disease.

Our third finding is that increased ER stress-mediated prnp gene expression protects cells from ER stressmediated cell death. This is shown by KD of PrP in MCF7 and MDA-MB-231 cells and in PrP null hippocampal cell lines. However, PrP does not protect HS578T cells from ER stress mediated cell death. These results indicate that the protective function of PrP may not be universal to breast carcinoma cells and that other pathways are involved. This is not unexpected given the complexity of cancers. Previous studies have shown that KD of PrP restores the susceptibility of TRAIL resistant MCF-7 cell lines [12] and over-expression of PrP induces MCF-7 resistance to TNF- $\alpha$-mediated cell death [13]. These results are entirely consistent with the previously reported protective role of PrP in MCF-7 cells $[4,12,13]$.

However, the mechanism by which PrP protects against ER stress is unclear here. We had previously shown that PrP could prevent Bax-mediated cell death in MCF-7 cells and in human primary neurons $[2,3]$, by preventing the conversion of Bax to pro-apoptotic Bax [4]. However, while we observe the activation of Bax with ER stress in these experiments, silencing PrP does not increase levels of Bax activation. Others have reported ER stress protective mechanisms against estrogen-deprived breast cancer cell death. One of the proposed mechanisms involves BiP directly. Zhou and colleagues identified that BiP protects MCF-7/BUS-10 estrogen starvation resistant cells by interacting with the $\mathrm{BH} 3$ domain pro-apoptotic protein $\mathrm{Bik}$, thus allowing the release of $\mathrm{Bcl}-2$ from Bik and increased survival via inhibition of Bax [73]. Other studies show that BiP can regulate cell death via both caspase-dependent and independent cell death [74], and that IGFBP-3 acts as a survival factor in the HS578T cell line via $\mathrm{BiP}$ and autophagy $[75,76]$. However, we show that $\operatorname{PrP} \mathrm{KD}$, while increasing protection against ER stress in MCF-7 cells, does not alter the levels of BiP. Therefore, we can exclude BiP as a direct regulator of survival through PrP. Together these results suggest that multiple 
protective pathways are involved in increasing breast cancer cell resistance to cell death.

Lastly, we describe that the ER stress-mediated increase in PrP levels is associated with increased cellular survival in human breast cancers. Our TMA analyses of human breast carcinomas showed that (a) high ER stress marker BiP levels were associated with higher PrP levels, (b) both $\mathrm{BiP}$ and PrP levels were higher in grade 3 tumors compared to grade 1 tumors, and (c) levels of PrP correlate with estrogen and progesterone receptor negative tumors. In three independent mRNA microarray analyses [52-54], higher levels of PrP mRNA were significantly associated with estrogen receptor negative cancers consistent with the previously reported higher resistance to adjuvant chemotherapy in estrogen receptor negative and $\operatorname{PrP}$ positive cancers [14]. Additionally, (a) two of the microarray analyses showed a significant reduction of progesterone receptor levels in high PrP expressing cancers [53,54], (b) one study showed a significant association of high $\operatorname{PrP}$ mRNA levels with tumor grade [54], and (c) one study showed a lower age at diagnostic [53] and an increase in metastatic events in high PrP mRNA tumors [53]. Furthermore, microarrays show that increased PrP mRNA levels are associated with ER stress in the most aggressive basal breast carcinoma cell lines compared with the less aggressive luminal cell lines ([55] and Figure 1). These results are consistent with findings that estrogen receptor positive breast cancers that are resistant to tamoxifen were shown to have increased sXBP1, indicating that increased ER stress conditions promote survival of luminal cancers [68]. These results indicate that higher PrP levels are associated with a poor outcome in breast cancer.

\section{Conclusions}

Together, these results indicate that ER stress increases levels of PrP that contribute to cell survival in some breast cancer cell lines. These results establish PRNP as a novel clinically relevant ER stress-regulated gene that may be implicated in increased survival of breast cancer tumor cells. Therefore, targeting the ER stress response and $\operatorname{PrP}$ may help in the treatment of a category of breast cancer tumors that are resistant to conventional treatments.

\footnotetext{
Abbreviations

4-PBA: 4-Phenyl-Butyric Acid; $\triangle$ ATF6a: Cleaved activating transcription factor 6a; AARE: Amino-acid-regulatory element; AMV: Avian myeloblastosis virus; ATF4: Activating transcription factor 4; ATF6a: Activating transcription factor 6a; BFA: Brefeldin A; BiP: Immunoglobulin heavy chain binding protein; ChIP: Chromatin immunoprecipitation; CHOP: CCAAT/enhancer-binding protein homologous protein; CHX: Cycloheximide; DMSO: Dimethyl sulfoxide; EDTA: Ethylenediaminetetraacetic acid; elF2a: Eukaryotic initiation factor 2a; ER: Endoplasmic reticulum; ERS: Estrogen; ERSE: ER stress responsive element; FBS: Fetal bovin serum; FLICA: SR Fluorochrome-labeled inhibitors of caspases; HEK 293: Human embryonic kidney 293; HRP: Horseradish peroxidase; IRE1a: Inositol-requiring enzyme 1a; KD: Knock down; PCR: Polymerase chain reaction; PERK: double-stranded RNA-activated protein
}

kinase-like ER kinase; PR: Progesterone; PrP: Prion protein; PRNP: Human prion protein gene; RLU: Relative luminescence units; SERCA: ER Ca-ATPase family; Thps: Thapsigargin; TM: Tunicamycin; TMA: Tissue microarray; TNF: tumor necrosis factor; TRAIL: Tumor Necrosis Factor-Alpha-Related ApoptosisInducing Ligand; UPR: Unfolded protein response; XBP1: X-Box protein-1.

\section{Authors' contributions}

$J J$ and MAD performed all experiments presented in this paper and participated in the writing of the manuscript. JUS performed the bioinformatics analyses on published databases. CF, SH and MB obtained patient consent and ethical approvals, and established the TMA and obtained medical information from patients. AL directed the study and wrote the manuscript. All authors meet the three authorship requirements described by the Journal. All authors approved the final draft of the manuscript for publication.

\section{Competing interests}

The authors declare that they have no competing interests.

\section{Acknowledgements}

We are grateful to Dr. J. Collinge (MRC Prion Unit, London, UK) for providing pGL-214 and pGL-538 vectors, Dr. R.J. Kaufman (University of Michigan Medical Center, Ann Arbor, MI, USA) for providing the pCGN-IRES-EGFP, pCGN-HA-splicedXBP1-IRES-EGFP, pCGN-ATF6 $\alpha$ and pCGN-HA-ATF4-IRESEGFP constructs and Paresa N. Giannopoulos for her technical help. This work was supported by Canadian Institutes of Health Research operating grants MOP89376 and MOP102738 to ALB. M-AD is the recipient of a Canadian Institutes of Health Research Frederick Banting and Charles Best doctoral award.

\section{Author details}

${ }^{1}$ Bloomfield Center for Research in Aging, Lady Davis Institute for Medical Research, Sir Mortimer B. Davis Jewish General Hospital, 3755 ch. Côte SteCatherine, Montréal, QC H3T 1E2, Canada. Department of Neurology and Neurosurgery, McGill University, 3801 University Street, Montréal, QC H3A 2B4, Canada. ${ }^{3}$ Segal Centre for Cancer Research, Lady Davis Institute for Medical Research, Sir Mortimer B. Davis Jewish General Hospital, 3755 ch. Côte Ste-Catherine, Montréal, QC H3T 1E2, Canada.

Received: 25 August 2012 Revised: 26 February 2013

Accepted: 1 March 2013 Published: 12 March 2013

\section{References}

1. Kuwahara C, Takeuchi AM, Nishimura T, Haraguchi K, Kubosaki A, Matsumoto Y, Saeki K, Yokoyama T, Itohara S, Onodera T: Prions prevent neuronal cell-line death. Nature 1999, 400:225-226.

2. Bounhar $Y$, Zhang $Y$, Goodyer $C G$, LeBlanc A: Prion protein protects human neurons against Bax-mediated apoptosis. J Biol Chem 2001, 276:39145-39149.

3. Roucou X, Guo Q, Zhang Y, Goodyer CG, LeBlanc AC: Cytosolic prion protein is not toxic and protects against Bax-mediated cell death in human primary neurons. J Biol Chem 2003, 278:40877-40881.

4. Roucou X, Giannopoulos PN, Zhang Y, Jodoin J, Goodyer CG, LeBlanc A: Cellular prion protein inhibits proapoptotic Bax conformational change in human neurons and in breast carcinoma MCF-7 cells. Cell Death Differ 2005, 12:783-795.

5. Bounhar Y, Mann KK, Roucou X, LeBlanc AC: Prion protein prevents Baxmediated cell death in the absence of other Bcl-2 family members in Saccharomyces cerevisiae. FEMS Yeast Res 2006, 6:1204-1212.

6. Lin DT, Jodoin J, Baril M, Goodyer CG, LeBlanc AC: Cytosolic prion protein is the predominant anti-Bax prion protein form: exclusion of transmembrane and secreted prion protein forms in the anti-Bax function. Biochim Biophys Acta 2008, 1783:2001-2012.

7. Laroche-Pierre S, Jodoin J, LeBlanc AC: Helix 3 is necessary and sufficient for prion protein's anti-Bax function. J Neurochem 2009, 108:1019-1031.

8. Brown DR, Schulz-Schaeffer WJ, Schmidt B, Kretzschmar HA: Prion proteindeficient cells show altered response to oxidative stress due to decreased SOD-1 activity. Exp Neurol 1997, 146:104-112.

9. Mitteregger G, Vosko M, Krebs B, Xiang W, Kohlmannsperger V, Nolting S, Hamann GF, Kretzschmar HA: The Role of the Octarepeat Region in 
Neuroprotective Function of the Cellular Prion Protein. Brain Pathol 2007, 17:174-183.

10. Moore RC, Mastrangelo P, Bouzamondo E, Heinrich C, Legname G, Prusiner SB, Hood L, Westaway D, DeArmond SJ, Tremblay P: Doppelinduced cerebellar degeneration in transgenic mice. Proc Natl Acad Sci USA 2001, 98:15288-15293.

11. Shmerling D, Hegyi I, Fischer M, Blattler T, Brandner S, Gotz J, Rulicke T, Flechsig E, Cozzio A, von Mering C: Expression of amino-terminally truncated PrP in the mouse leading to ataxia and specific cerebellar lesions. Cell 1998, 93:203-214.

12. Meslin F, Hamai A, Gao P, Jalil A, Cahuzac N, Chouaib S, Mehrpour M: Silencing of prion protein sensitizes breast adriamycin-resistant carcinoma cells to TRAlL-mediated cell death. Cancer Res 2007, 67:10910-10919.

13. Diarra-Mehrpour M, Arrabal S, Jalil A, Pinson X, Gaudin C, Pietu G, Pitaval A, Ripoche H, Eloit M, Dormont D, Chouaib S: Prion protein prevents human breast carcinoma cell line from tumor necrosis factor alpha-induced cell death. Cancer Res 2004, 64:719-727.

14. Meslin F, Conforti R, Mazouni C, Morel N, Tomasic G, Drusch F, Yacoub M, Sabourin JC, Grassi J, Delaloge S, Mathieu MC, Chouaib S, Andre F, Mehrpour M: Efficacy of adjuvant chemotherapy according to Prion protein expression in patients with estrogen receptor-negative breast cancer. Ann Oncol 2007, 18:1793-1798.

15. Li C, Yu S, Nakamura F, Yin S, Xu J, Petrolla AA, Singh N, Tartakoff A, Abbott DW, Xin W, Sy MS: Binding of pro-prion to filamin A disrupts cytoskeleton and correlates with poor prognosis in pancreatic cancer. J Clin Invest 2009, 119:2725-2736.

16. Li C, Yu S, Nakamura F, Pentikainen OT, Singh N, Yin S, Xin W, Sy MS: Proprion binds filamin $\mathrm{A}$, facilitating its interaction with integrin beta1, and contributes to melanomagenesis. J Biol Chem 2010, 285:30328-30339.

17. Liang J, Pan YL, Ning XX, Sun LJ, Lan M, Hong L, Du JP, Liu N, Liu CJ, Qiao TD, Fan DM: Overexpression of PrPC and its antiapoptosis function in gastric cancer. Tumour Biol 2006, 27:84-91.

18. Wang JH, Du JP, Zhang YH, Zhao XJ, Fan RY, Wang ZH, Wu ZT, Han Y: Dynamic changes and surveillance function of prion protein expression in gastric cancer drug resistance. World J Gastroenterol 2011, 17:3986-3993.

19. Pan Y, Zhao L, Liang J, Liu J, Shi Y, Liu N, Zhang G, Jin H, Gao J, Xie H, Wang J, Liu Z, Fan D: Cellular prion protein promotes invasion and metastasis of gastric cancer. FASEB J 2006, 20:1886-1888.

20. Liang J, Pan Y, Zhang D, Guo C, Shi Y, Wang J, Chen Y, Wang X, Liu J, Guo X, Chen Z, Qiao T, Fan D: Cellular prion protein promotes proliferation and G1/S transition of human gastric cancer cells SGC7901 and AGS. FASEB J 2007, 21:2247-2256

21. Liang J, Bai F, Luo G, Wang J, Liu J, Ge F, Pan Y, Yao L, Du R, Li X, Fan R Zhang H, Guo X, Wu K, Fan D: Hypoxia induced overexpression of $\operatorname{PrP}(\mathrm{C})$ in gastric cancer cell lines. Cancer Biol Ther 2007, 6:769-774.

22. Liang J, Luo G, Ning $X$, Shi Y, Zhai H, Sun S, Jin H, Liu Z, Zhang F, Lu Y, Zhao Y, Chen X, Zhang H, Guo X, Wu K, Fan D: Differential expression of calcium-related genes in gastric cancer cells transfected with cellular prion protein. Biochem Cell Biol 2007, 85:375-383.

23. Liang J, Ge F, Guo C, Luo G, Wang X, Han G, Zhang D, Wang J, Li K, Pan Y, Yao L, Yin Z, Guo X, Wu K, Ding J, Fan D: Inhibition of PI3K/Akt partially leads to the inhibition of $\operatorname{PrP}(\mathrm{C})$-induced drug resistance in gastric cancer cells. FEBS J 2009, 276:685-694.

24. McEwan JF, Windsor ML, Cullis-Hill SD: Antibodies to prion protein inhibit human colon cancer cell growth. Tumour Biol 2009, 30:141-147.

25. Li QQ, Sun YP, Ruan CP, Xu XY, Ge JH, He J, Xu ZD, Wang Q, Gao WC: Cellular prion protein promotes glucose uptake through the Fyn-HIF2alpha-Glut1 pathway to support colorectal cancer cell survival. Cancer Sci 2011, 102:400-406.

26. Antonacopoulou AG, Palli M, Marousi S, Dimitrakopoulos FI, Kyriakopoulou U, Tsamandas AC, Scopa CD, Papavassiliou AG, Kalofonos HP: Prion protein expression and the M129V polymorphism of the PRNP gene in patients with colorectal cancer. Mol Carcinog 2010, 49:693-699.

27. Jodoin J, Laroche-Pierre S, Goodyer CG, LeBlanc AC: Defective retrotranslocation causes loss of anti-Bax function in human familial prion protein mutants. J Neurosci 2007, 27:5081-5091.

28. Bridges JP, Xu Y, Na CL, Wong HR, Weaver TE: Adaptation and increased susceptibility to infection associated with constitutive expression of misfolded SP-C. J Cell Biol 2006, 172:395-407.

29. Tabuchi Y, Takasaki I, Kondo T: Identification of genetic networks involved in the cell injury accompanying endoplasmic reticulum stress induced by bisphenol A in testicular Sertoli cells. Biochem Biophys Res Commun 2006, 345:1044-1050.

30. Ron D, Walter P: Signal integration in the endoplasmic reticulum unfolded protein response. Nat Rev Mol Cell Biol 2007, 8:519-529.

31. Kaufman RJ: Stress signaling from the lumen of the endoplasmic reticulum: coordination of gene transcriptional and translational controls. Genes Dev 1999, 13:1211-1233.

32. Prostko CR, Brostrom MA, Brostrom CO: Reversible phosphorylation of eukaryotic initiation factor 2 alpha in response to endoplasmic reticular signaling. Mol Cell Biochem 1993, , 127-128: 255-265.

33. Hampton RY: ER stress response: getting the UPR hand on misfolded proteins. Curr Biol 2000, 10:R518-521.

34. Schroder M, Kaufman RJ: The mammalian unfolded protein response. Annu Rev Biochem 2005, 74:739-789.

35. Yoshida H, Haze K, Yanagi H, Yura T, Mori K: Identification of the cis-acting endoplasmic reticulum stress response element responsible for transcriptional induction of mammalian glucose-regulated proteins. Involvement of basic leucine zipper transcription factors. J Biol Chem 1998, 273:33741-33749.

36. Yoshida H, Matsui T, Yamamoto A, Okada T, Mori K: XBP1 mRNA is induced by ATF 6 and spliced by IRE1 in response to ER stress to produce a highly active transcription factor. Cell 2001, 107:881-891.

37. Harding HP, Zhang Y, Bertolotti A, Zeng $H$, Ron D: Perk is essential for translational regulation and cell survival during the unfolded protein response. Mol Cell 2000, 5:897-904

38. Kokame K, Kato H, Miyata T: Identification of ERSE-II, a new cis-acting element responsible for the ATF6-dependent mammalian unfolded protein response. J Biol Chem 2001, 276:9199-9205.

39. Kakiuchi $C$, Ishiwata M, Hayashi A, Kato T: XBP1 induces WFS1 through an endoplasmic reticulum stress response element-like motif in SH-SY5Y cells. J Neurochem 2006, 97:545-555.

40. Li M, Baumeister P, Roy B, Phan T, Foti D, Luo S, Lee AS: ATF6 as a transcription activator of the endoplasmic reticulum stress element: thapsigargin stress-induced changes and synergistic interactions with NF-Y and YY1. Mol Cell Biol 2000, 20:5096-5106.

41. Ma Y, Brewer JW, Diehl JA, Hendershot LM: Two distinct stress signaling pathways converge upon the CHOP promoter during the mammalian unfolded protein response. J Mol Biol 2002, 318:1351-1365.

42. Roy B, Lee AS: The mammalian endoplasmic reticulum stress response element consists of an evolutionarily conserved tripartite structure and interacts with a novel stress-inducible complex. Nucleic Acids Res 1999, 27:1437-1443.

43. Ubeda M, Habener JF: CHOP gene expression in response to endoplasmic-reticular stress requires NFY interaction with different domains of a conserved DNA-binding element. Nucleic Acids Res 2000, 28:4987-4997.

44. Healy SJ, Gorman AM, Mousavi-Shafaei P, Gupta S, Samali A: Targeting the endoplasmic reticulum-stress response as an anticancer strategy. Eur J Pharmacol 2009, 625:234-246.

45. Koumenis C: ER stress, hypoxia tolerance and tumor progression. Curr Mol Med 2006, 6:55-69.

46. Hassan S, Baccarelli A, Salvucci O, Basik M: Plasma stromal cell-derived factor-1: host derived marker predictive of distant metastasis in breast cancer. Clin Cancer Res 2008, 14:446-454.

47. Lin JH, Li H, Yasumura D, Cohen HR, Zhang C, Panning B, Shokat KM, Lavail MM, Walter P: IRE1 signaling affects cell fate during the unfolded protein response. Science 2007, 318:944-949.

48. Mahal SP, Asante EA, Antoniou M, Collinge J: Isolation and functional characterisation of the promoter region of the human prion protein gene. Gene 2001, 268:105-114.

49. Wang $Y$, Shen J, Arenzana N, Tirasophon W, Kaufman RJ, Prywes R: Activation of ATF6 and an ATF6 DNA binding site by the endoplasmic reticulum stress response. J Biol Chem 2000, 275:27013-27020.

50. Bommiasamy H, Back SH, Fagone P, Lee K, Meshinchi S, Vink E, Sriburi R, Frank M, Jackowski S, Kaufman RJ, Brewer JW: ATF6alpha induces XBP1independent expansion of the endoplasmic reticulum. J Cell Sci 2009, 122:1626-1636

51. Kouskouti A, Scheer E, Staub A, Tora L, Talianidis I: Gene-specific modulation of TAF10 function by SET9-mediated methylation. Mol Cell 2004, 14:175-182. 
52. van de Vijver MJ, He YD, van't Veer LJ, Dai H, Hart AA, Voskuil DW, Schreiber GJ, Peterse JL, Roberts C, Marton MJ, Parrish M, Atsma D, Witteveen A, Glas A, Delahaye L, van der Velde T, Bartelink H, Rodenhuis S, Rutgers ET, Friend SH, Bernards R: A gene-expression signature as a predictor of survival in breast cancer. N Engl J Med 2002, 347:1999-2009.

53. Minn AJ, Gupta GP, Siegel PM, Bos PD, Shu W, Giri DD, Viale A, Olshen AB, Gerald WL, Massague J: Genes that mediate breast cancer metastasis to lung. Nature 2005, 436:518-524.

54. Chin K, DeVries S, Fridlyand J, Spellman PT, Roydasgupta R, Kuo WL, Lapuk A, Neve RM, Qian Z, Ryder T, Chen F, Feiler H, Tokuyasu T, Kingsley C, Dairkee S, Meng Z, Chew K, Pinkel D, Jain A, Ljung BM, Esserman L, Albertson DG, Waldman FM, Gray JW: Genomic and transcriptional aberrations linked to breast cancer pathophysiologies. Cancer Cell 2006, 10:529-541.

55. Neve RM, Chin K, Fridlyand J, Yeh J, Baehner FL, Fevr T, Clark L, Bayani N, Coppe JP, Tong F, Speed T, Spellman PT, DeVries S, Lapuk A, Wang NJ, Kuo WL, Stilwell JL, Pinkel D, Albertson DG, Waldman FM, McCormick F, Dickson RB, Johnson MD, Lippman M, Ethier S, Gazdar A, Gray JW: A collection of breast cancer cell lines for the study of functionally distinct cancer subtypes. Cancer Cell 2006, 10:515-527.

56. Kubota K, Niinuma Y, Kaneko M, Okuma Y, Sugai M, Omura T, Uesugi M, Uehara T, Hosoi T, Nomura Y: Suppressive effects of 4-phenylbutyrate on the aggregation of Pael receptors and endoplasmic reticulum stress. J Neurochem 2006, 97:1259-1268.

57. Yoshida H, Okada T, Haze K, Yanagi H, Yura T, Negishi M, Mori K: ATF6 activated by proteolysis binds in the presence of NF-Y (CBF) directly to the cis-acting element responsible for the mammalian unfolded protein response. Mol Cell Biol 2000, 20:6755-6767.

58. Bi M, Naczki C, Koritzinsky M, Fels D, Blais J, Hu N, Harding H, Novoa I, Varia M, Raleigh J, Scheuner D, Kaufman RJ, Bell J, Ron D, Wouters BG, Koumenis C: ER stress-regulated translation increases tolerance to extreme hypoxia and promotes tumor growth. EMBO J 2005, 24:3470-3481.

59. Kazemi S, Mounir Z, Baltzis D, Raven JF, Wang S, Krishnamoorthy JL, Pluquet $\mathrm{O}$, Pelletier J, Koromilas AE: A novel function of elF2alpha kinases as inducers of the phosphoinositide-3 kinase signaling pathway. $\mathrm{Mol} B \mathrm{BiO}$ Cell 2007, 18:3635-3644.

60. Puthalakath H, O'Reilly LA, Gunn P, Lee L, Kelly PN, Huntington ND, Hughes PD, Michalak EM, McKimm-Breschkin J, Motoyama N, Gotoh T, Akira $S$, Bouillet $P$, Strasser A: ER stress triggers apoptosis by activating BH3-only protein Bim. Cell 2007, 129:1337-1349.

61. Basler K, Oesch B, Scott M, Westaway D, Walchli M, Groth DF, McKinley MP, Prusiner SB, Weissmann C: Scrapie and cellular PrP isoforms are encoded by the same chromosomal gene. Cell 1986, 46:417-428.

62. Funke-Kaiser $H$, Theis S, Behrouzi T, Thomas A, Scheuch K, Zollmann FS, Paterka M, Paul M, Orzechowski HD: Functional characterization of the human prion protein promoter in neuronal and endothelial cells. J Mol Med 2001, 79:529-535.

63. Puckett C, Concannon P, Casey C, Hood L: Genomic structure of the human prion protein gene. Am J Hum Genet 1991, 49:320-329.

64. Bellingham SA, Coleman LA, Masters CL, Camakaris J, Hill AF: Regulation of prion gene expression by transcription factors SP1 and metal transcription factor-1. J Biol Chem 2009, 284:1291-1301.

65. Qin K, Zhao L, Ash RD, McDonough WF, Zhao RY: ATM-mediated transcriptional elevation of prion in response to copper-induced oxidative stress. J Biol Chem 2009, 284:4582-4593.

66. Vincent B, Sunyach C, Orzechowski HD, St George-Hyslop P, Checler F: p53Dependent transcriptional control of cellular prion by presenilins. J Neurosci 2009, 29:6752-6760.

67. Westaway D, Cooper C, Turner S, Da Costa M, Carlson GA, Prusiner SB: Structure and polymorphism of the mouse prion protein gene. Proc Natl Acad Sci USA 1994, 91:6418-6422.

68. Davies MP, Barraclough DL, Stewart C, Joyce KA, Eccles RM, Barraclough R, Rudland PS, Sibson DR: Expression and splicing of the unfolded protein response gene XBP-1 are significantly associated with clinical outcome of endocrine-treated breast cancer. Int J Cancer 2008, 123:85-88.

69. Mehrpour M, Codogno P: Prion protein: from physiology to cancer biology. Cancer Lett 2010, 290:1-23.

70. Hetz C, Castilla J, Soto C: Perturbation of endoplasmic reticulum homeostasis facilitates prion replication. J Biol Chem 2007, 282:12725-12733.
71. Orsi A, Fioriti L, Chiesa R, Sitia R: Conditions of endoplasmic reticulum stress favor the accumulation of cytosolic prion protein. J Biol Chem 2006, 281:30431-30438.

72. Rane NS, Kang SW, Chakrabarti O, Feigenbaum L, Hegde RS: Reduced translocation of nascent prion protein during ER stress contributes to neurodegeneration. Dev Cell 2008, 15:359-370.

73. Zhou H, Zhang Y, Fu Y, Chan L, Lee AS: Novel mechanism of antiapoptotic function of 78-kDa glucose-regulated protein (GRP78): endocrine resistance factor in breast cancer, through release of B-cell lymphoma 2 (BCL-2) from BCL-2-interacting killer (BIK). J Biol Chem 2011, 286:25687-25696.

74. Cook KL, Shajahan AN, Warri A, Jin L, Hilakivi-Clarke LA, Clarke R: Glucoseregulated protein 78 controls cross-talk between apoptosis and autophagy to determine antiestrogen responsiveness. Cancer Res 2012, 72:3337-3349.

75. Grkovic S, O'Reilly VC, Han S, Hong M, Baxter RC, Firth SM: IGFBP-3 binds GRP78, stimulates autophagy and promotes the survival of breast cancer cells exposed to adverse microenvironments. Oncogene 2012.

76. Li C, Harada A, Oh Y: IGFBP-3 sensitizes antiestrogen-resistant breast cancer cells through interaction with GRP78. Cancer Lett 2012, 325:200-206

doi:10.1186/bcr3398

Cite this article as: Déry et al:: Endoplasmic reticulum stress induces PRNP prion protein gene expression in breast cancer. Breast Cancer Research 2013 15:R22.

\section{Submit your next manuscript to BioMed Central and take full advantage of:}

- Convenient online submission

- Thorough peer review

- No space constraints or color figure charges

- Immediate publication on acceptance

- Inclusion in PubMed, CAS, Scopus and Google Scholar

- Research which is freely available for redistribution

Submit your manuscript at www.biomedcentral.com/submit
Biomed Central 